\title{
1 Marine Bacterial Models for Experimental Biology
}

\author{
Raphaël Lami, Régis Grimaud, Sophie Sanchez-Brosseau, Christophe Six, \\ François Thomas, Nyree / West, Fabien Joux and Laurent Urios
}

\section{CONTENTS}

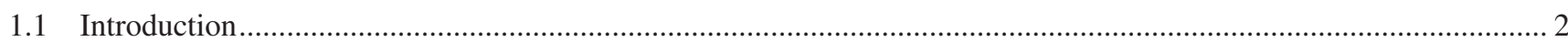

1.1.1 Early Bacterial Models in Experimental Biology .................................................................................. 2

1.1.2 A Vast Diversity of Bacteria in the Seawater, a Reservoir of Potential Prokaryotic Models............................ 2

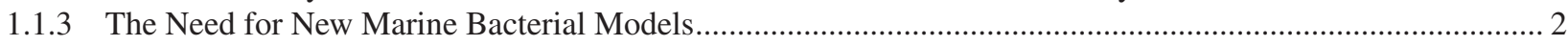

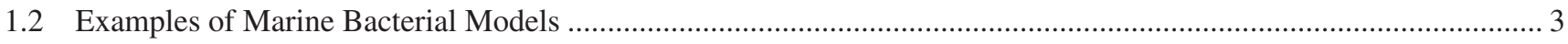

1.2.1 Vibrio fischeri, a Well-Known and Historic Marine Bacterial Model ............................................................ 3

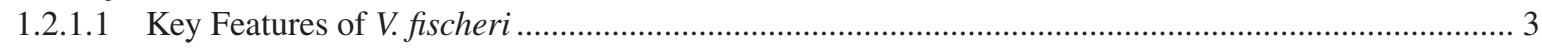

1.2.1.2 Bioluminescence Mechanisms in Marine Environments and Organisms.......................................... 3

1.2.1.3 Quorum Sensing, a Cell-to-Cell Communication System ............................................................... 4

1.2.1.4 The Molecular Mechanisms of Symbiotic Associations.............................................................. 4

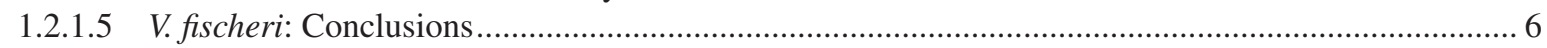

1.2.2 Picocyanobacteria as Models to Explore Photosynthetic Adaptations in the Oceans ...................................... 6

1.2.2.1 Key Features of Prochlorococcus and Synechococcus ................................................................. 6

1.2.2.2 Different Adaptive Strategies of Prochlorococcus and Synechococcus to Light ............................... 7

1.2.2.3 Adaptation of the Photosynthetic Apparatus of Prochlorococcus ...................................................... 7

1.2.2.4 Adaptation of the Photosynthetic Apparatus of Synechococcus ...................................................... 7

1.2.2.5 Picocyanobacterial Models: Conclusions .................................................................................... 9

1.2.3 Zobellia galactanivorans, a Model for Bacterial Degradation of Macroalgal Biomass.................................... 9



1.2.3.2 An Extraordinary Set of Enzymes Made Z. galactanivorans a Bacterial Model

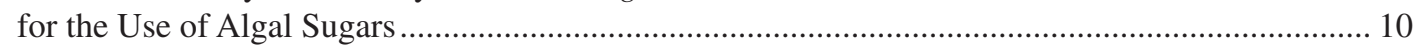

1.2.3.3 A Model to Study Bacterial Colonization of Algal Surfaces ............................................................ 12

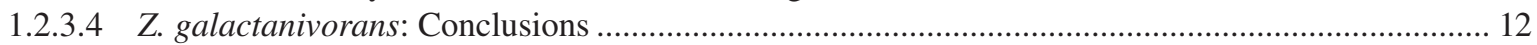

1.2.4 Marinobacter hydrocarbonoclasticus, a Model Bacterium for Biofilm Formation,

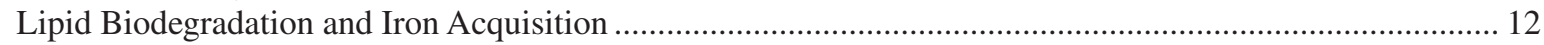

1.2.4.1 Key Features of Marinobacter hydrocarbonoclasticus .................................................................. 12

1.2.4.2 Biofilm Formation on Nutritive Surface and Alkane Degradation ............................................... 12

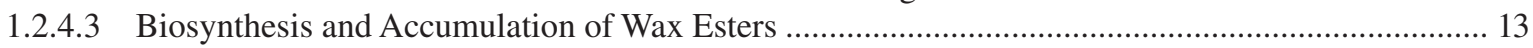

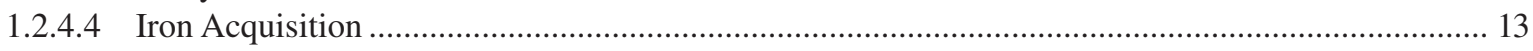



1.2.4.6 Marinobacter hydrocarbonoclasticus: Conclusions.......................................................................14

1.3 The Bacterial Model Organism Toolkit ....................................................................................................

1.3.1 Innovative Techniques for the Isolation of New Bacterial Models: Culturing the Unculturable ......................14



1.3.3 The Future of Gene Editing in Bacterial Models: The CRISPR-Cas Approaches ..............................................17

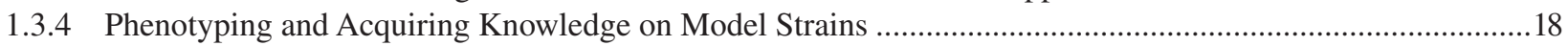

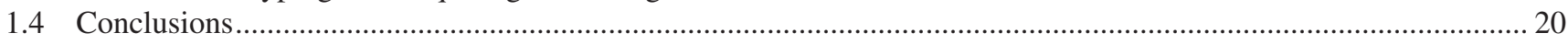

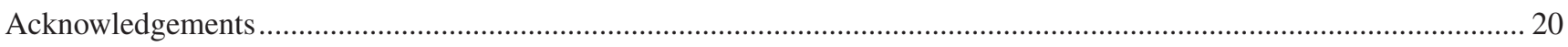

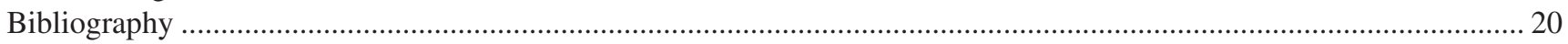




\section{$1.1 \quad$ INTRODUCTION}

Bacteria are ubiquitous and abundant in the marine environment $\left(10^{5}-10^{6}\right.$ cells. $\left.\mathrm{mL}^{-1}\right)$, playing a multiplicity of roles in marine ecosystems that is a product of their long evolution and subsequent genetic diversification. Certain species play key roles in biogeochemical cycles, notably by contribution to primary production in the case of phototrophic Cyanobacteria or by the remineralization of this production by heterotrophic bacteria. Other bacterial species impact human health and the economy adversely by causing disease in humans and aquaculture facilities, whereas others interact in a coordinated fashion to form biofilms that can lead to biofouling and corrosion of marine structures. Conversely, by virtue of their wide genetic diversity, the bacterial kingdom offers a chemical and enzymatic diversity that can be exploited in many fields, for example, in the bioremediation of marine pollution or for the discovery of novel natural products for the food and medical industries. To further understanding in these diverse research domains, simple tractable bacterial model organisms are needed. In this chapter, we will briefly touch on the well-known nonmarine bacterial model organisms and the criteria for a good model organism and explain some of the reasons few marine models are available despite the extraordinary reservoir of the marine environment. We will then present four different marine bacterial models applied to very different research domains, each with their own specific questions and applications but all dependent on a similar toolkit that we will develop at the end of this chapter.

\subsubsection{Eariy Bacterial Models in Experimental Biology}

One of the most famous model organisms is undoubtedly the intestinal bacterium Escherichia coli belonging to the Proteobacteria phylum that was discovered in 1885 by Theodor Escherich. With its fast growth rate in a range of inexpensive media, simple cell structure and ease of manipulation and storage, $E$. coli became the workhorse of the microbiology laboratory. With advances in molecular biology, research on $E$. coli led to a number of significant discoveries that were instrumental in developing the field of molecular genetics. A few examples of these discoveries, some of which were awarded Nobel prizes, include gene exchange between bacteria by conjugation, the elucidation of the genetic code, the mechanism of DNA replication, the organization of genes into operons and restriction enzymes (Blount 2015).

Other bacteria are also well-known models in biology, although less commonly used, and not so famous as E. coli. Bacillus subtilis is a member of the Firmicutes phylum and can be found in a diverse number of aquatic and terrestrial habitats and even in animal guts (Earl et al. 2008). On account of its fast growth, natural transformation, protein secretion, production of endospores and formation of biofilms, it has become an important model, notably for the food and biotechnology industries (Errington and van der Aart 2020). Despite being non-pathogenic, this bacterium has also been used to study the mechanisms of pathogenesis, as it presents some interesting features in common with pathogenic cells, including biofilm formation and sporulation. Other medically important model bacteria include Staphylococcus for the study of the skin microbiota and antibiotic resistance; Bifidobacterium for research on gut microbiota; and Pseudomonas aeruginosa for biofilm formation, chemotaxis and antibiotic resistance.

\subsubsection{A Vast Diversity of Bacteria in the Seawater, a Reservoir of Potential Prokaryotic Models}

Understandably, the best-known models mentioned previously are those organisms living in close contact with humans, as commensals or present in their immediate environment. The exploration of the oceans, combined with the molecular biology revolution, revealed a vast diversity of bacteria. Prokaryotes are incredibly abundant in seawater: their average abundance is about $5 \times 10^{5}$ cells per $\mathrm{mL}$, and their total number in the world ocean is estimated to be about $10^{29}$ cells (Whitman et al. 1998). Since the 1990s, continuous and massive 16S rRNA gene sequencing of planktonic DNA has revealed the extraordinary diversity of marine prokaryotes, both for Bacteria and Archaea. An analysis of samples collected during the Tara research vessel's marine expeditions (https://oceans.taraexpeditions.org) has revealed 37,470 species of Bacteria and Archaea (Sunagawa et al. 2015). Analysis of sequence datasets has also revealed that we are still far from capturing the whole picture of the total prokaryotic diversity in the oceans. A considerable fraction of this diversity belongs to the "rare biosphere", an immense reservoir of species with low abundances (Overmann and Lepleux 2016). Moreover, recent studies revealed that some marine niches, like marine biofilms, are even more diverse than the pelagic waters and still constitute a substantial source of hidden diversity (Zhang et al. 2019). The recovery of large metagenomic datasets from oceanic samples has also provided evidence for the extraordinary functional diversity of marine prokaryotes; in their 193 samples, the Tara Ocean datasets revealed the presence of 39,246 different orthologous groups. The oceanic metagenomic datasets were enriched in functional categories related to transport of solutes (coenzymes, lipids, amino acids, secondary metabolites) and energy production (including photosynthesis) (Sunagawa et al. 2015). Marine bacteria are also known to produce many types of bioactive compounds that are of interest for industrial applications, including active enzymes and molecules with anticancer, antimicrobial and anti-inflammatory properties (Zeaiter et al. 2018).

\subsubsection{The Need for New Marine Bacterial Models}

The marine environment is potentially a very important reservoir of prokaryotic models to explore many types of biological mechanisms, either to investigate their diversity 
or to assess some of the particular features linked to their adaptation to marine life. We will emphasize in this chapter the diversity of biological questions that can be addressed using marine models and for which the current 'traditional' models cannot provide enough answers. Indeed, many major questions in biology and evolutionary studies cannot be fully addressed using famous bacterial models like $E$. coli or $B$. subtilis. Many of them are connected to environmental questions, and they include, for example, the ones related to molecular adaptations to environmental changes (including in ecotoxicology) or to the identification of organisms suited to develop innovative 'green' or 'blue' biotechnological applications.

\subsection{EXAMPLES OF MARINE BACTERIAL MODELS}

Only a few marine bacterial models currently exist, a paradox when considering the huge taxonomic and functional diversity of marine waters. In this chapter, we present a nonexhaustive collection of relevant marine models and give a snapshot of the diversity of biological mechanisms they can help us explore. We will show how Vibrio fischeri is a common model to examine host-symbiont interactions, bioluminescence mechanisms and cell-cell interactions; how marine cyanobacteria Prochlorococcus and Synechococcus are models to examine the mechanisms of photosynthesis and their adaptation to life in the oceans; how Zobellia galactanivorans allows us to study the bacterial degradation of algal biomass; and how Marinobacter hydrocarbonoclasticus provides us with key information on biofilm development, iron acquisition and hydrocarbon and lipid metabolism.

\subsubsection{Vibrio fischeri, a Well-Known and Historic Marine Bacterial Model}

Allivibrio fischeri (but the historical name $V$. fischeri is still widely used) is a widely known bacterial model isolated from the marine environment. We will see in this section that this bacterium serves as a model for the study of bioluminescence mechanisms, cell-to-cell communication systems and host-symbiont relationships. This first example will reveal how a marine bacterial model also serves to explore relevant mechanisms in medical sciences, biotechnology, pharmacology and many others.

\subsubsection{Key Features of $V$. fischeri}

This bacterium is a common marine Gammaproteobacteria that belongs to the Vibrionaceae. This bacterium is motile thanks to a tuft of polar flagella, which is formed by one to five flagellar filaments. The genome of $V$. fischeri has been fully sequenced and is of $4.2 \mathrm{Mb}$. It is organized in two chromosomes and usually some additional plasmids. This bacterium colonizes various marine niches, including the seawater column and marine sediments. One exceptional feature of this bacterium is its ability to colonize hosts, like the small squid Euprymna scolopes: when associated with its host, $V$. fischeri produces light, which makes the animal luminescent.

\subsubsection{Bioluminescence Mechanisms in Marine Environments and Organisms}

Bioluminescent marine bacteria interact with a high diversity of metazoan hosts, including squids and fishes. Like some other marine bioluminescent bacteria, V. fischeri exhibits a dual lifestyle, either freely floating in the water column or as a symbiont inside its host. V. fischeri is typically involved in symbiosis species from two families of squids as well as different families of fishes (Dunlap and Kita-Tsukamoto 2006), thus demonstrating the ubiquitous capacity of the bacterium to colonize different host types. Among the family Sepiolidae, the symbioses involving Mediterranean (Sepiola) and Pacific (Euprymna) squid species probably evolved independently, as they involve different Vibrio species (Fidopiastis et al. 1998). It is known that the light organ of Sepiola sp. contains a mixed population of V. logei and V. fischeri species (Fidopiastis et al. 1998), while only $V$. fischeri is strictly observed in the light organ of Euprymna scolopes. It appears that most of the time, the bacterial population is monospecific in a light organ (Dunlap and Urbanczyk 2013).

As for all bioluminescent organisms, the chemical reaction of bioluminescence in bacteria relies on the oxidation of a substrate (luciferin) by an enzyme (luciferase). Bacterial luciferin consists of a reduced flavin $\left(\mathrm{FMNH}_{2}\right)$ and an aliphatic aldehyde chain (4 to 8 carbon atoms), which serves as a cofactor. Bacterial luciferase is a flavin mono-oxygenase formed of two $\alpha$ (40 kDa or $355 \mathrm{aa}$ ) and $\beta$ (37 kDa or $324 \mathrm{aa})$ subunits. The catalytic site of the enzyme consists of a TIMtype barrel (Campbell et al. 2010) located in the $\alpha$ subunit, while the $\beta$ subunit is necessary for the stability and activity of the enzyme. In V. fischeri, luminescence is produced when luciferase (composed of $\alpha$ and $\beta$ subunits) converts reduced flavin to flavin. During the dioxygen-dependent reaction, $\mathrm{FMNH}_{2}$ and the aliphatic aldehyde are oxidized to flavin (FMN) and fatty acid, respectively, as follows: $\mathrm{FMNH}_{2}+$ $\mathrm{O}_{2}+\mathrm{R}-\mathrm{CHO} \rightarrow \mathrm{FMN}+\mathrm{R}-\mathrm{COOH}+\mathrm{H}_{2} \mathrm{O}+\mathrm{hu}\left(\lambda_{\max }=490\right.$ $\mathrm{nm}$ ). Early studies evidenced that a $V$. fischeri strain (previously also known as Photobacterium fischeri) was also able to emit yellow light (Ruby and Nealson 1977). This was one of the first descriptions of a bioluminescent bacterial strain emitting light in a different color than blue-green, which is the more common emission in the ocean water column. In this particular case of fluorescence associated with bioluminescence phenomenon, a yellow fluorescent protein, YFP, binds FMN and shifts the light emission from around 490 $\mathrm{nm}$ to $545 \mathrm{~nm}$. In luminous bacteria, all products involved in the bioluminescent reaction are encoded in a lux operon. In $V$. fischeri, the lux operon comprises genes coding for different subunits of either luciferase (luxA and luxB), fatty acid reductase complex of the luminescence system (luxC, luxD, and luxE) or flavin reductase (luxG) (Dunlap and Kita-Tsukamoto 2006). In V. fischeri, the lux genes are 
cotranscribed with luxI (which will be defined hereafter), according to the luxICDABEG order, the most frequent order found in luminous bacteria.

\subsubsection{Quorum Sensing, a Cell-to-Cell Communication System}

The existence of communication between microorganisms was first suspected in Streptococcus pneumoniae by Alexander Tomasz in 1965. The researcher demonstrated the emission of a hormone-like based communication that controls the competent state. However, most of the observations that led to the study of communication between microorganisms and thus to the concept of "quorum sensing" were acquired from experiments conducted by marine scientists during the 1970s. During this decade, and as described, in-depth studies were conducted on $V$. fischeri strains that can colonize the light organ of the Hawaiian bobtail squid Euprymna scolopes, where they produce bioluminescence (Greenberg et al. 1979; Nealson et al. 1970). In particular, it has been noticed that the capacity for bioluminescence is a density-dependent phenotype. In seawater, $V$. fischeri cells are free living and scarce and do not produce light most of the time. However, in particular conditions, they can emit light when they reach high cell densities, like in laboratory cultures or when they colonize the light organ of the small squid. Since these initial studies, the concept of quorum sensing was defined in the 1990s and refers to a population density-based physiological response of bacterial cells (Fuqua et al. 1994).

After these first observations, this original system of bioluminescence regulation was fully chemically and genetically described. The diffusible signal, also named autoinducer (AI), was identified in 1981 as an acyl-homoserine lactone (AHL) and described as 3-oxo-hexanoyl-homoserine lactone (3-oxo-C6-HSL) (Eberhard et al. 1981). The genetic cluster involved in this phenomenon was then characterized as a bi-directionally transcribed operon with eight genes, named luxA-E, luxG, luxI and luxR. This genetic system has been mentioned in this chapter, except for the roles of LuxI and LuxR, which are of particular interest when focusing on quorum sensing mechanisms. LuxI is the AI synthase, while LuxR is the receptor of this diffusible signal. When the AIs reach a threshold concentration in the nearby environment of bacterial cells (reflecting the increase in cell abundance), they bind to the LuxR receptors, which act as transcription factors and activate the expression of all lux genes. The diffusible signal is designated as AI because it promotes its own production through the autoinduction of luxI (Engebrecht et al. 1983; Swartzman et al. 1990) (Figure 1.1).

After these initial discoveries and the subsequent identification of the genetic system of quorum sensing in $V$. fischeri, the study of this mechanism garnered little interest from the scientific community for more than a decade. Likely, quorum sensing appeared then to be a kind of regulation specialized for bioluminescence expressed in the Vibrio bacteria colonizing a small Hawaiian squid. This interest was renewed in the 1990s with the development of DNA sequencing methods and the discovery of a broad diversity of luxI and luxR homologs in many different types of bacteria: Vibrio fisheri has thus been little by little established as a universal model for the study of quorum sensing circuits.

Most of the scientific effort in the field of quorum sensing in the 1990s focused on strains with a medical or agronomic interest. An important reason for this interest in the medical field, among others, is that an increasing number of links were established between virulence and quorum sensing in model pathogenic bacteria, such as in Staphylococcus strains (Ji et al. 1995) and Pseudomonas aeruginosa (Pearson et al. 2000). It was only in the following decade that work began to be published about bacteria in the field of environmental sciences, including those isolated from marine waters. In 1998, one of the first reports of AIs present in the natural environment was published under the title "Quorum Sensing Autoinducers: Do They Play a Role in Natural Microbial Habitats?", which revealed some early interest in quorum sensing from the aquatic AIs in naturally occurring biofilms (Bachofen and Schenk 1998). In 2002, Gram et al. reported for the first time the production of AHLs within Roseobacter strains isolated from marine snow (Gram et al. 2002). Since then, a growing number of reports have focused on the nature and role of quorum sensing in marine bacteria, and large sets of culture-dependent and culture-independent studies have highlighted the importance of quorum sensing mechanisms in marine biofilms and environments (Lami 2019).

\subsubsection{The Molecular Mechanisms of Symbiotic Associations}

Nowadays, the symbiosis between $V$. fischeri and the Hawaiian bobtail squid Euprymna scolopes is well characterized (McFallNgai and Ruby 1991) and constitutes a perfect model to understand bacteria-animal interactions (McFall-Ngai 2014). The luminescence produced by the $V$. fischeri symbionts would help camouflage their host at night by eliminating its shadow within the water column ("counter-illumination"). Although this symbiosis is obligatory for the host, symbionts are horizontally transmitted as the squid host E. scolopes acquires its $V$. fischeri luminescent symbionts from the surrounding seawater (Wei and Young 1989). This association shows a strong species specificity initiated within hours after the juvenile squid hatches, provided that symbiotically competent $V$. fischeri cells are present in the ambient seawater (Ruby and Asato 1993; Wei and Young 1989).

Interestingly, the E. scolopes $-V$. fischeri model provided the first direct evidence of an animal host controlling the number and activity of its extracellular bacterial population as part of a circadian biological rhythm. E. scolopes and Sepiola atlantica mechanically control the emission of luminescence by periodically expelling excess $V$. fischeri symbionts, thereby adjusting bacterial density inside the light organ (Ruby and Asato 1993). As a result, the cell abundance of $V$. fischeri within the squid follow a circadian pattern. At night, $V$. fischeri cells are present at high concentrations in the crypts of the light organ $\left(10^{10}-10^{11}\right.$ cells $\left.\mathrm{mL}^{-1}\right)$ and produce 


\section{LOW CELL DENSITY}

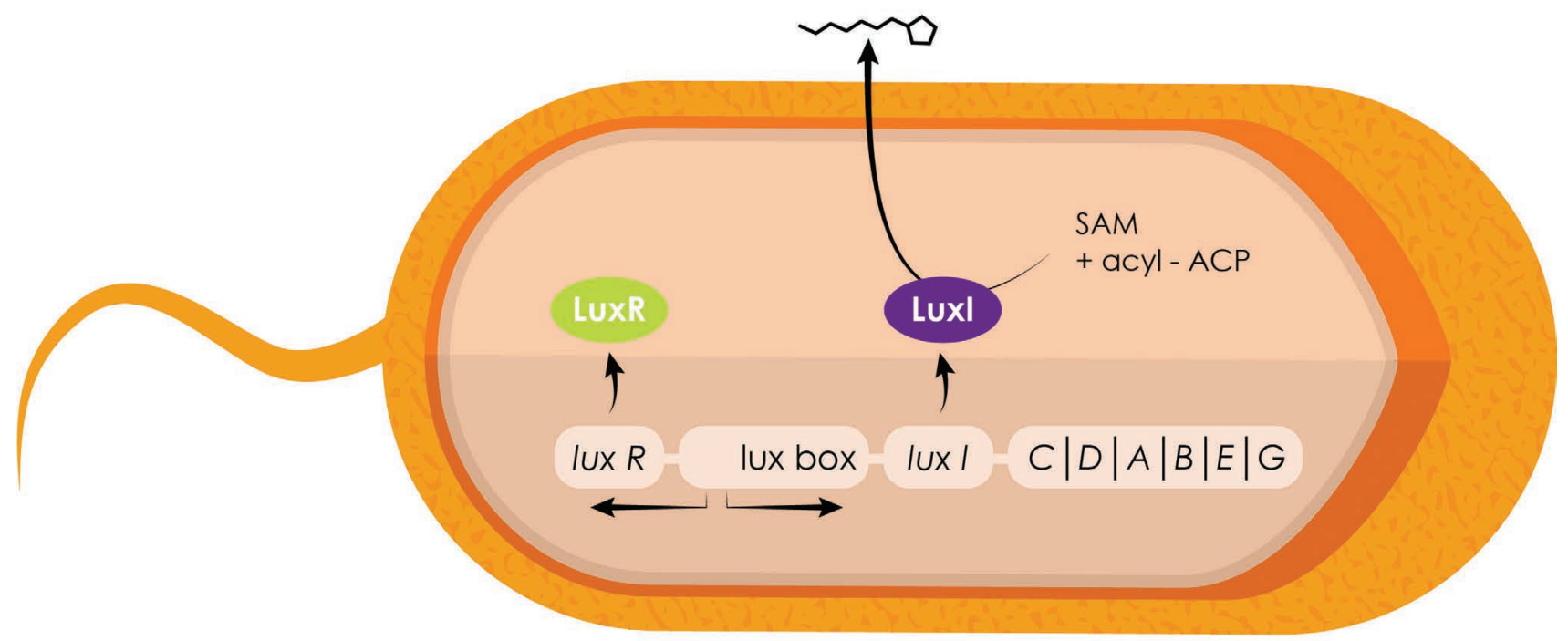

\section{HIGH CELL DENSITY}

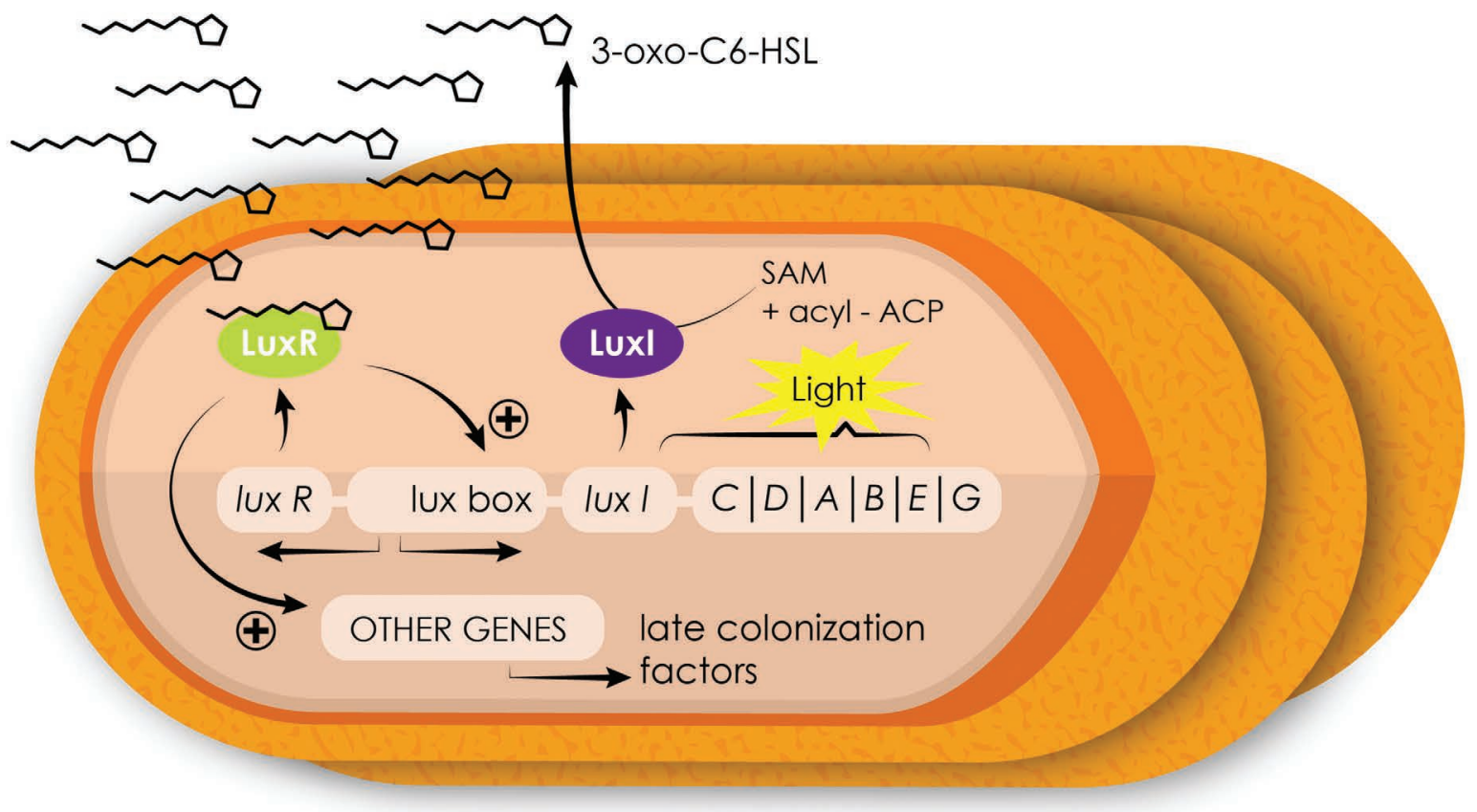

FIGURE 1.1 A schematic representation of the first discovered luxI/luxR-based quorum sensing system in the model species Vibrio fischeri, producing 3-oxo-C6-HSL as an autoinducer. Since then, a second quorum sensing system has been discovered. Based on the AinS AI synthase, it permits the liberation of C8-HSL. At low cell density, autoinducer concentration is low, while at high cell densities, autoinducers induce cytoplasmic cascades that lead to drastic genetic modifications, including transcription of genes responsible for bacterial bioluminescence.

AIs, which induce light emission (see previous paragraph). At the end of the night, most of the bacterial cells are expulsed from the light organ, leading to a dramatic reduction in bacterial concentration and of this diffusible factor. Thus, in the $V$. fischeri-E. scolopes symbiosis, the lowest production of bioluminescence is observed just before dawn to early afternoon. This coincides with the onset of environmental light (Lee and Ruby 1994). During the day, the concentrations of $V$. fischeri cells that have not been expulsed are very low, the diffusible factor is not produced and the squid does not glow. 
However, this remaining population of $V$. fischeri grows steadily under favorable conditions within the squid throughout the day and at night again reaches a cell abundance that is sufficient to produce bioluminescence (Boettcher et al. 1996; Heath-Heckman et al. 2013).

A complex and specific dialog occurs between V. fischeri cells and the E. scolopes host, given that first, the $V$. fischeri cells are typically present at a concentration of less than $0.1 \%$ of the total bacterial population in the Hawaiian waters (Lee and Ruby 1994), and second, the motility of these bacterial cells is required to bring the symbionts toward the pores, the entrance of the luminescent organ in formation. Two main mechanisms were found to initiate the interaction (Visick and McFall-Ngai 2000): (i) close contact between the surfaces of the host and symbiont cells through receptorligand interactions and (ii) the creation of an environment in which only $V$. fischeri is viable. Receptor-ligand dynamics, often more generally referenced as microbe-associated molecular patterns (MAMPs) (Koropatnick 2004), can also be essential elements underlying the onset, maturation and persistence of mutualistic animal-microbe partnerships. Different data provided evidence that at least a portion of the host response is mediated by lipopolysaccharide-binding proteins from the LBP/BPI protein family (Chun et al. 2008; Krasity et al. 2011) and peptidoglycan-recognition proteins (PGRPs) (Troll et al. 2010). Also, studies were published concerning the complete annotated genome of $V$. fischeri (Ruby et al. 2005) and the cDNA expression libraries for colonized and uncolonized E. scolopes light organs (Chun et al. 2006). Numerous gene-encoding proteins known to be essential for both development and symbiosis were identified, such as reflectin, actin, myeloperoxidase, aldehyde dehydrogenase and nitric oxide synthase (Chun et al. 2008). These findings confirm the molecular dialogue between host squid and bacterial symbionts at cell surfaces. Comparison of host and symbiont population transcriptomes at four times over the day-night cycle revealed maximum expression of cytoskeleton related genes just before dawn, concordant with the daily effacement of the host epithelium and a cyclic change in the anaerobic metabolism of the symbionts (Wier et al. 2010). These host epithelium effacement and change in symbiont metabolism are clearly synchronized with the daily expulsion of most of the bacterial population (Boettcher et al. 1996; Ruby and Asato 1993). It is well known that during the colonization of the host tissue, the expression of sets of bacterial genes can be under the control of specific transcriptional regulators (Cotter and DiRita 2000), mainly described in bacteria that initiate pathogenic or benign infections (van Rhijn and Vanderleyden 1995). Interestingly, a mutant study showed that the gene litR, essential for the induction of luminescence, also plays a role as a transcriptional regulator in modulating the ability of $V$. fischeri to colonize juvenile squid (Fidopiastis et al. 2002).

\subsubsection{V. fischeri: Conclusions}

$V$. fischeri is now a well-known marine model in experimental biology. This first example clearly reveals how a marine bacterial strain, which at first sight appears to have a very particular mode of life (a bacterium associated with Hawaiian species), is in fact a universal model to explore mechanisms relevant to many diverse scientific fields and is at the origin of major discoveries in biology.

\subsubsection{Picocyanobacteria as Models to Explore Photosynthetic Adaptations in the Oceans}

Cyanobacteria are, evolutionarily speaking, very old organisms capable of producing oxygen that have significantly contributed to shape the current composition of the atmosphere. Their bioenergetic mechanisms are unique, as complex electron transfers (photosynthesis and respiration) occur in the same cell compartment. Among these organisms, the marine picocyanobacteria Prochlorococcus and Synechococcus genera provide detailed examples of photosynthetic adaptations to light conditions in the oceans. Beyond the description of unique photosynthetic mechanisms, the study of these marine cyanobacteria is key to better understanding the evolutionary origins of photosynthesis.

\subsubsection{Key Features of Prochlorococcus and Synechococcus}

The global chlorophyll biomass of oceanic ecosystems is dominated by tiny unicellular cyanobacteria of the Prochlorococcus and Synechococcus genera $(\sim 1$ and 0.6 $\mu \mathrm{m}$ diameter, respectively), which are thought to account for $\sim 25 \%$ of the global marine primary productivity (Flombaum et al. 2013). They are considered the smallest but also the numerically most abundant photosynthetic organisms on Earth, with estimations of $1.7 \times 10^{27}$ cells in the World Ocean. Prochlorococcus and the marine Synechococcus diverged from a common ancestor $~ 150$ million years ago, and the Prochlorococcus radiation delineates a monophyletic lineage within the complex Synechococcus group. Marine Synechococcus strains are indeed a more ancient and diverse radiation, which is usually divided into three subclusters, the major one (5.1) being subdivided into $\sim 15$ other important clades that include 35 subclades (Farrant et al. 2016; Mazard et al. 2012). Despite their close relatedness, these two cyanobacteria have quite different ecophysiological features, as they occupy complementary though overlapping ecological niches in the ocean. Prochlorococcus strains are confined to the warm $45^{\circ} \mathrm{N}$ to $40^{\circ} \mathrm{S}$ latitudinal band and are very abundant in the subtropical gyres and the Mediterranean Sea but are absent from the high-latitude, colder waters. Prochlorococcus cell concentrations are often less important in coastal areas than offshore. By contrast, Synechococcus cells are detected in almost all marine environments outside of the polar circles and can be considered as the most widespread cyanobacterial genus on Earth.

Since the discovery of marine Prochlorococcus and Synechococcus only some decades ago, much progress has been made in the study of their biology. Marine picocyanobacteria have been prime targets for whole-genome sequencing projects, and more than 100 complete genomes 
are now available, spanning a large range of ecological niches and physiological and genetic diversity. These studies have revealed that Prochlorococcus is a striking example of an organism that has undergone genome "streamlining" (Dufresne et al. 2005), an evolutionary process thought to have rapidly followed the divergence from the common ancestor with Synechococcus and which resulted in an rapid specialization in oligotrophic marine niches. Thus, some Prochlorococcus isolates have a genome as small as $1.65 \mathrm{Mb}$ ( $\sim 1700$ genes), and this cyanobacterium is often considered as approaching the near-minimal set of genes necessary for an oxygenic phototroph. The study of the Synechococcus genomes is more complex because of the large microdiversity of the radiation. They are on the whole bigger $(2-3 \mathrm{Mb}$; 2500-3200 genes) than Prochlorococcus ones and, by contrast, show a relatively small range of variation in their characteristics among strains (Dufresne et al. 2008). Interestingly, the number of "unique genes", that is, the genes that are found only in one genome, is well correlated with the whole genome size. Like in Prochlorococcus, most of these unique genes are located in variable regions called genomic islands, whose size, position and predicted age are highly variable among genomes. This suggests that horizontal transfer of genetic material is an important process in these picocyanobacteria. Overall, the Synechococcus core genome includes $\sim 70$ gene families that are not present in Prochlorococcus, suggesting a higher diversity of metabolic processes, in line with the greater diversity of marine niches colonized by Synechococcus (Scanlan et al. 2009).

\subsubsection{Different Adaptive Strategies of Prochlorococcus and Synechococcus to Light}

The accumulation of (meta)genomic information has triggered the beginning of a thorough analysis of the relationships between the picocyanobacterial genotypes, phenotypes and different marine environments. In particular, the study of Prochlorococcus and Synechococcus has allowed much progress in the understanding of the selective pressures that drive the evolution of the oxygenic photosynthetic process at all scales of organization, from genes to the global ocean. Light quantity and quality are among the main drivers of photosynthesis, both showing great variability in the oceans. In tropical oligotrophic areas, the sunray angle and water transparency lead the photic zone to extend much deeper compared to higher latitudes and in turbid coastal waters. Moreover, seawater absorbs and scatters wavelengths in a selective way. Long wavelengths such as red light are absorbed within the first meters, whereas bluegreen light can penetrate more deeply. In shallow coastal areas, water often carries large amounts of particulate matter that further alter the underwater light quality, inducing the presence of a green-yellow light. Successful adaptation of phototrophs to the multifaceted behavior of light in the aquatic systems notably relies on the nature and composition of the light-harvesting systems, and Prochlorococcus and Synechococcus have adopted drastically different strategies.

\subsubsection{Adaptation of the Photosynthetic Apparatus of Prochlorococcus}

The most-reviewed example is probably the manner by which Prochlorococcus modified its photosynthetic apparatus during evolution (Ting et al. 2002). Most cyanobacteria on Earth have a photosynthetic antenna consisting of a giant pigmented protein complex, called the phycobilisome. By contrast, Prochlorococcus is one of the rare cyanobacteria that uses membrane-intrinsic chlorophyll-binding proteins, termed Prochlorophyte-chl-binding (Pcb) proteins. Thus, most genes encoding phycobilisome components have been lost during the Prochlorococcus genome streamlining. As Prochlorococcus uses chlorophyll $b$ as an accessory pigment in its atypical antenna complex, it efficiently harvests blue light, the dominant wavelength in oligotrophic and deep waters. As a result, Prochlorococcus populations extend deeper in the water column than almost any other phototrophs, basically defining the deepest limit of photosynthetic life in the World Ocean. The ability of Prochlorococcus to thrive in the entire euphotic zone also largely relies on its microdiversity, as this cyanobacteria features genetically and photophysiologically distinct populations (Biller et al. 2014). These so-called high-light and low-light ecotypes partition themselves down the water column along the light irradiance decreasing gradient. One of the main known physiological differences between Prochlorococcus light ecotypes is their major light-harvesting complexes, which comprise different sets of the Pcb proteins associated either with photosystem I or II, resulting in higher chl $\mathrm{b}$ to chl a ratio in the low-light ecotypes (Partensky and Garczarek 2010). Nevertheless, we still know very little about the differential pigmentation and function of the different Pcb proteins, especially regarding the photoprotective processes. More physiological and biochemical work is needed on this topic (Figure 1.2).

\subsubsection{Adaptation of the Photosynthetic Apparatus of Synechococcus}

A second interesting example is the way picocyanobacteria deal with the large variations in light spectral quality that occur along the horizontal (i.e. coastal-oceanic) gradients in the oceans. In contrast to Prochlorococcus, marine Synechococcus use phycobilisomes to harvest light, which consist of three classes of stacked phycobiliproteins. The phycobilisome core, made of allophycocyanin (APC) and connected to the photosystems, is surrounded by rods constituted of phycocyanin (PC) and/or phycoerythrin (PE). Each phycobiliprotein has a much-conserved hexameric cylindrical structure, binding one or several tetrapyrrolic chromophore (phycobilin) types: the blue phycocyanobilin (PCB), the red phycoerythrobilin (PEB), and the orange phycourobilin (PUB).

During their evolution, marine Synechococcus have developed an amazing variety of pigmentations by exploiting the modular nature of phycobilisomes, elaborating rods with variable pigment composition. Thus, three main pigment types can be distinguished based on the phycobiliprotein 


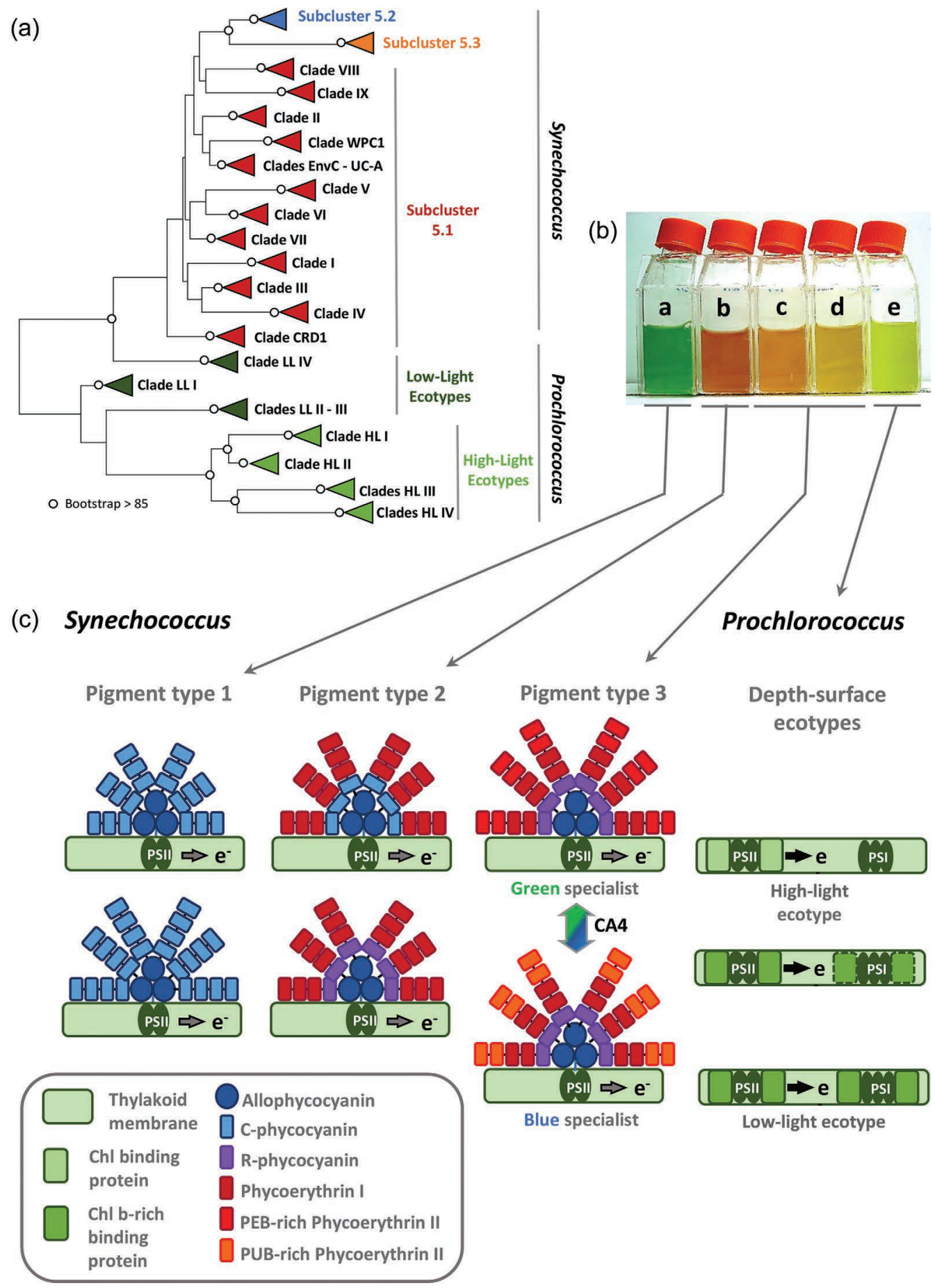

FIGURE 1.2 (a) Phylogenetic diagram (neighbor joining) showing the main marine picocyanobacterial lineages. Circled nodes are supported by bootstrap values higher than 85 , and the other nodes are not well resolved; for further information. Subcluster 5.1 is the most diversified Synechococcus group. In contrast to Synechococcus, Prochlorococcus global phylogeny shows a microdiversification dependent on the light niche. (b) Batch cultures of Synechococcus spp. strains RS9917 (a), WH7805 (b), WH7803 (c), WH8102 (d) and Prochlorococcus sp. MED4 (e), illustrating different pigment types and their corresponding photosynthetic antenna system. (c) Synechococcus pigment type 1 includes C-phycocyanin rich strains with phycobilisome rods of different lengths, and pigment type 2 includes strains with one phycoerythrobilin (PEB)-rich phycoerythrin and either a C- or R-phycocyanin. Synechococcus pigment type 3 strains use the most sophisticated phycobilisome, including R-phycocyanin and two types of phycoerythrins with different possible proportions of PEB and phycourobilin (PUB), depending on the strain. Some strains can tune the PUB to PEB ratio through the chromatic acclimation (CA4) process. Strains of the different pigments are dispersed in the radiation and do not constitute clades, betraying the occurrence of horizontal transfer of phycobilisome related genes (see text). The represented structures of the phycobilisomes (homogeneity and number of rods, phycobiliproteins per rod, etc.) are putative. For Prochlorococcus, the antenna system is composed of Pcb proteins intrinsic to the thylakoidal membranes. High-light ecotypes can have a naked PSI, while low-light ecotypes may have additional Pcbs around it, sometimes inducible upon certain conditions. ([a] Mazard et al. 2012; Farrant et al. 2016.) 
and phycobilin content of the phycobilisome rods. Pigment type 1 contains only phycocyanin, binding solely the orange light-absorbing phycocyanobilin $\left(\mathrm{A}_{\mathrm{MAX}}=620 \mathrm{~nm}\right)$, and is restricted to coastal, low-salinity surface waters, characterized by a high turbidity, inducing the dominance of orange wavelengths in the water. Pigment type 2 strains use PC and one type of PE binding PEB, the green-light absorbing pigment $\left(\mathrm{A}_{\mathrm{MAX}}=550 \mathrm{~nm}\right)$, and inhabit transition zones between brackish and oceanic environments with intermediate optical properties. Finally, pigment type 3 strains possess PC and two types of PEs (PE-I and PE-II), a feature specific of marine Synechococcus cyanobacteria. The PEs of pigment type 3 strains bind both PEB and the blue lightabsorbing PUB $\left(\mathrm{A}_{\mathrm{MAX}}=495 \mathrm{~nm}\right)$ in various ratios depending on the strain, thus defining "green light specialists" (low PUB:PEB) and "blue light specialists" (high PUB:PEB) strains. Accordingly, these strains are found over large gradients from onshore mesotrophic waters, rich in green wavelengths, to offshore oligotrophic systems, where blue light is dominant. Overall, at least a dozen of optically different phycobiliproteins have been elaborated by marine Synechococcus during their evolution (Six et al. 2007), and there is no doubt that this is partly responsible for their global ecological success.

The genomic comparison of strains representative of these pigment types revealed that most genes involved in the biosynthesis of phycobilisome rods are located in a large (up to $\sim 30 \mathrm{~kb}$ ) specialized region of the genome, generally predicted to be a genomic island. The gene content and organization of this region is specific to each pigment type, independently from the strain phylogenetic position, and shows a tremendous increase in phycobilisome gene complexity from pigment types 1 to 3 , the latter type being a more recent structure and the most sophisticated phycobilisome known so far. Together with the presence of phycobilisome genes in metaviriome datasets, this suggests that genes related to the phycobilisome rod region can be laterally transferred between Synechococcus lineages and that this might be a key mechanism facilitating adaptation of these lineages to new light niches.

Finally, there exists another particularly interesting Synechococcus pigment type that consists of strains capable of a unique type of chromatic acclimation (CA4), a reversible process that modifies the composition of the phycobilisomes. The strains capable of CA4 are pigment type 3 strains able to dynamically tune the PUB to PEB ratio of their phycobilisome, which becomes low under green light and high under blue light to precisely match the ambient light quality. $\mathrm{CA}$ is therefore predicted to increase fitness in conditions of changing light colors, allowing the harvesting of more photons than for strains with fixed pigmentation. Comparative genomic analyses of marine Synechococcus strains showed that the CA4 process is possible thanks to a specific small genomic island that exists in two slightly different versions, named CA4-A and CA4-B (Humily et al. 2013). The recent implementation of methods for plating and genetic manipulations such as the disruption and/or overexpression of CA4 genes in marine Synechococcus has allowed us to start deciphering the regulation of the CA4-A process. Thus, in the model strain Synechococcus sp. RS9916, isolated in the Red Sea, the CA-4 process involves chromophore switch systems at three phycoerythrin cysteines, which are regulated by the two transcription factors FciA and FciB (Sanfilippo et al. 2019). Thanks to the setup of genetic transformation methods, CA is one of the physiological processes that has been more closely studied in the laboratory in picocyanobacteria.

Using phycobiliprotein and CA4 genetic markers, the study of the extensive metagenomic Tara Oceans dataset allowed us to determine that, globally, CA4-A and CA4-B strains account for 23\% and 19\% of all Synechococcus, respectively (Grébert et al. 2018). Interestingly, CA4-A cells predominated in the nutrient-rich, temperate or cold waters found at high latitudes and in upwelling areas, while CA4-B cells were most abundant in warm, nutrient-poor waters. The reason there exist two types of CA4 genomic islands is, however, still not clear, and the functioning of the CA4-B genomic island is under investigation.

\subsubsection{Picocyanobacterial Models: Conclusions}

Picocyanobacteria (meta)genomics has greatly increased our understanding of the genomic and phenotype variations existing among these organisms, which is tightly linked to processes of niche specialization. In particular, these studies have unveiled unprecedented information on how photosynthetic complexes may drastically evolve in the oceans to fit different light niches. In this context, it is worth noting that the strength of the picocyanobacterial model is not restricted to one model organism but rather consists in a large panel of many strains that allow the understanding of the evolution of major processes like photosynthesis in the oceans. To better understand the relationships between picocyanobacterial genotypes and phenotypes, further progress requires a significant development of experimental work on the numerous picocyanobacteria strains available in culture. In this context, the development of culture axenization methods adapted to picocyanobacteria is a real necessity. Compared to other microbial models, thorough and advanced physiological studies are still scarce, and today, targeted studies of gene function should be prioritized over the overaccumulation of non-characterized genetic information. The recent development of genetic manipulation techniques on the Synechococcus sp. RS9916 strain gives much hope, but this will be particularly challenging for Prochlorococcus.

\subsubsection{Zobellia galactanivorans, a Model for Bacterial Degradation of Macroalgal Bıomass}

Macroalgae and their associated microbiota provide a large diversity of enzymes, in particular involved in the degradation of many diverse types of sugars, which are also of major interest for industry. Numerous economic sectors rely on the production of efficient enzymes and are continuously searching for innovative ones. For example, alginate 
lyases have many applications for food and pharmaceutical companies. We will see in this section that the bacterium $Z$. galactanivorans, associated with macroalgae, is an excellent model to study the diversity and the functioning of these enzymes. Working on this bacterial model also provides interesting insights into the mechanisms of colonization of algal surfaces and degradation of macroalgal organic matter.

\subsubsection{Key Features of Zobellia galactanivorans}

Green, red and brown macroalgae (also known as seaweeds) are dominant primary producers in coastal regions, often locally exceeding phytoplankton and other benthic carbon fixers (Duarte et al. 2005). Seaweeds thus represent an important reservoir of organic matter and are considered a global carbon sink. The composition of macroalgal biomass is unique and consists of $>50 \%$ of polysaccharides that differ from those known in terrestrial plants by the nature of their monosaccharide units and the presence of sulfated motifs and other substituents (Ficko-Blean et al. 2014). Turnover of this biomass is mostly mediated by marine heterotrophic bacteria that can colonize macroalgae and access, degrade and remineralize the algal compounds. Studies of the mechanisms underlying the interactions of these bacteria with macroalgae and their degradation pathways are therefore crucial to understanding coastal ecosystems' nutrient cycles and discovering novel enzymatic functions.

Members of the class Flavobacteriia (phylum Bacteroidetes) are recognized as key players in the degradation of marine algal polysaccharides (Thomas et al. 2011b). Among them, the cultivated species $Z$. galactanivorans has become over the past 20 years an environmentally relevant model organism to investigate macroalgal biomass degradation. Both cultivation and metagenomic approaches frequently detect members of the genus Zobellia in algae-dominated habitats and directly on the surface of seaweeds from different oceanic basins (Hollants et al. 2013; Nedashkovskaya et al. 2004). In particular, Z. galactanivorans Dsij ${ }^{\mathrm{T}}$ was first isolated in November 1988 in Roscoff (France) from a live specimen of the red macroalga Delesseria sanguinea (Potin et al. 1991) and later described as the type strain of the genus Zobellia (Barbeyron et al. 2001). Cells are Gram-negative and rod-shaped with rounded ends $(0.3-0.5 \times 1.2-8.0 \mu \mathrm{m}) . Z$. galactanivorans is chemoorganotroph with a strictly aerobic respiratory metabolism. Colonies on agar plates are yelloworange due to the biosynthesis of non-diffusible flexirubintype pigments. Cells do not possess flagella and cannot swim in liquid medium. On solid surfaces, they exhibit gliding motility at ca. $1-4 \mu \mathrm{m} \cdot \mathrm{s}^{-1}$.

\subsubsection{An Extraordinary Set of Enzymes Made Z. galactanivorans a Bacterial Model for the Use of Algal Sugars}

Z. galactanivorans $\mathrm{Dsij}^{\mathrm{T}}$ has been extensively studied for its ability to use a wide array of macroalgal compounds as sole carbon and energy sources, including agars and carrageenans from red algae, as well as alginate, laminarin, mannitol and fucose-containing sulfated polysaccharides from brown algae. Recently, it was also shown to directly degrade fresh tissues of the kelp Laminaria digitata, corroborating its efficiency for macroalgal biomass turnover (Zhu et al. 2017). Annotation of its 5.5-Mb genome revealed that up to $9 \%$ of its gene content could be dedicated to polysaccharide utilization (Barbeyron et al. 2016). This includes genes encoding an impressive number of 142 glycoside hydrolases (GHs) and 17 polysaccharide lyases (PLs), representing 56 different functional carbohydrate active enzyme families (CAZymes), together with 37 carbohydrate-binding modules as described in the CAZy database (Lombard et al. 2014). These enzymes are accompanied by 18 carbohydrate esterases and 71 sulfatases of the S1 family, which can remove substituents from polysaccharides. These genes are often clustered in regions of the $Z$. galactanivorans genome termed polysaccharide utilization loci (PULs). PULs are frequently found in Bacteroidetes. They encode a suite of proteins dedicated to the utilization of a given polysaccharide, generally comprising (i) CAZYmes responsible for the breakdown of the substrate, (ii) substituent-removing enzymes, (iii) substratebinding membrane proteins, (iv) transporters for oligosaccharides and (v) transcriptional regulators that control the PUL expression, depending on substrate availability. In particular, Z. galactanivorans $\mathrm{Dsij}^{\mathrm{T}}$ harbors 71 tandems of SusC-like TonB-dependent transporter (TBDT) and SusD-like surface glycan-binding protein (SGBP) that are considered hallmarks of PUL genomic organization (Grondin et al. 2017).

Over the years, numerous biochemical and structural studies have focused on the in-depth characterization of Z. galactanivorans proteins dedicated to polysaccharide utilization. In September 2020, the function of 42 of these proteins was experimentally validated, and for half of them, the crystallographic 3D structure was solved. This notably includes enzymes targeting agars (Naretto et al. 2019), porphyrans (Hehemann et al. 2010), carrageenans (MatardMann et al. 2017), laminarin (Labourel et al. 2015), alginate (Thomas et al. 2013), mannitol (Groisillier et al. 2015) and hemicellulose (Dorival et al. 2018). In several instances, studies of $Z$. galactanivorans proteins led to the discovery of novel CAZY families [e.g. iota-carrageenases GH82 and $\alpha$-1,3-L-(3,6-anhydro)-galactosidase GH117 (Rebuffet et al. 2011)] or to novel activities in existing families [e.g. exolytic a-1,3-(3,6-anhydro)-D-galactosidases in GH127 and GH129 (Ficko-Blean et al. 2017)].

Furthermore, genome-wide transcriptomes of Z. galactanivorans $\mathrm{Dsij}^{\mathrm{T}}$ cells grown with different carbohydrates are publicly available, either based on microarrays (Thomas et al. 2017) or RNA-seq (Ficko-Blean et al. 2017). This is complemented by a validated reverse transcription realtime quantitative PCR (RT-qPCR) protocol to specifically target genes of interest (Thomas et al. 2011a). These transcriptomic data revealed both substrate-specific and shared responses between co-occurring polysaccharides and helped define 192 operon-like transcription units. The upregulation of 35 predicted transcriptional regulators in the presence of algal polysaccharides compared to glucose gave further insights into the regulation strategies at play to fine-tune 
gene expression depending on the rapidly changing glycan landscape. This was recently exemplified by the characterization of the regulator AusR, a transcriptional repressor controlling the expression of the $Z$. galactanivorans alginolytic system (Dudek et al. 2020). In addition, genetic tools were adapted for Z. galactanivorans, including protocols for transposon random mutagenesis, site-directed mutagenesis and complementation (Zhu et al. 2017). Integration of all these complementary tools now opens the way for functional investigations of full catabolic pathways, as illustrated by studies on $Z$. galactanivorans alginate utilization system (AUS) (Thomas et al. 2012) and carrageenan utilization system (CUS) (Ficko-Blean et al. 2017). Both systems rely on complex regulons comprising genes within and distal to a PUL and encode the full set of proteins necessary to sense the substrates, degrade polysaccharides into their monosaccharide constituents and assimilate them into the central metabolism. Interestingly, site-directed mutants of the CUS unveiled (i) the complementary functions of two $\alpha-1,3-(3,6$-anhydro)-D-galactosidases that were otherwise

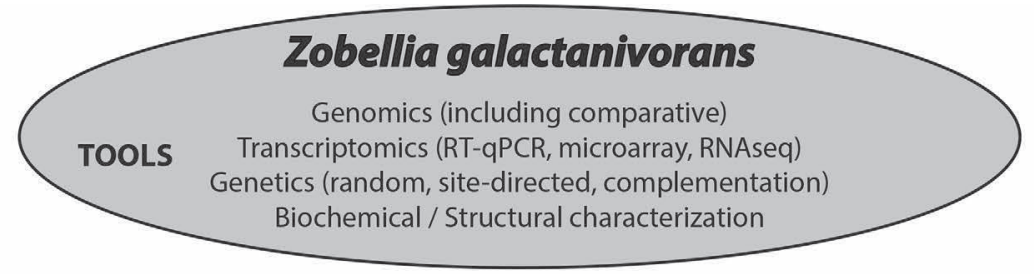

\section{DEGRADATION OF ALGAL BIOMASS}

\section{Gene content}

$142 \mathrm{GH}, 45$ families

$17 \mathrm{PL}, 11$ families

$18 \mathrm{CE}$, 9 families

37 CBM, 14 families

71 sulfatases $\mathrm{S} 1,17$ families

71 TBDT/SusD-like tandems
Transcriptomic responses

upregulated genes vs. glucose

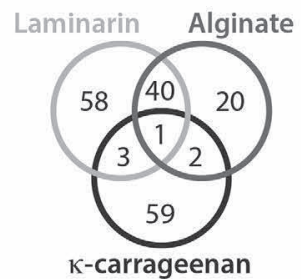

PUL organization

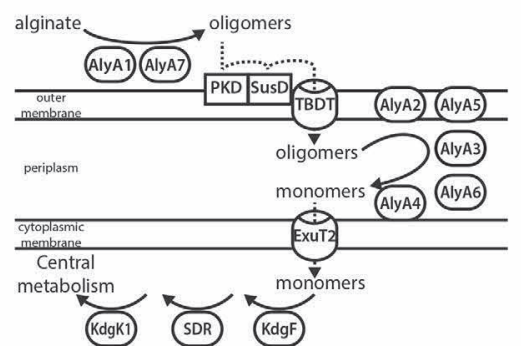

CARRAGEENAN UTILIZATION SYSTEM

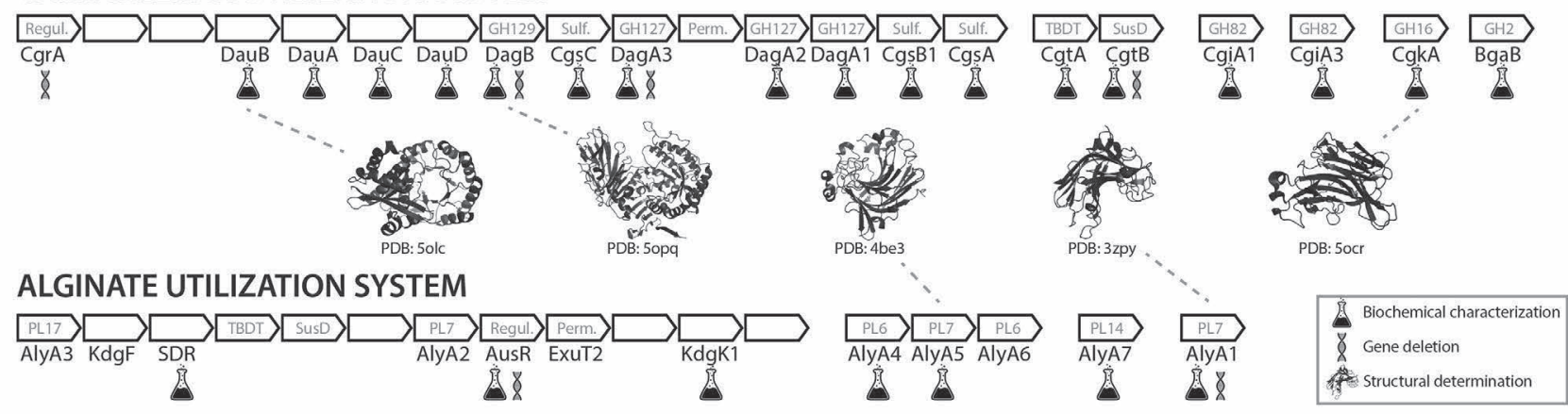

\section{COLONIZATION OF ALGAL TISSUES}

Invasion

Adhesion to surfaces

Gliding motility

Biofilm formation
Resistance

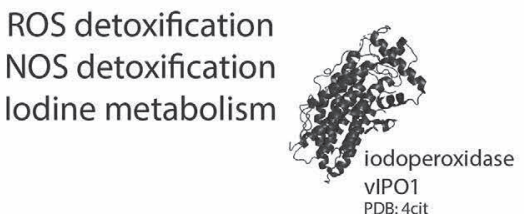

Competition

Acyl-homoserine lactone acylase Antibiotic production<smiles>CC(C)CCCCCCc1c(O)cc(CCCCCC(C)C)cc1O</smiles>

FIGURE 1.3 Schematic view of the multifaceted model organism Z. galactanivorans. The currently available experimental tools are listed, together with selected features that make Z. galactanivorans a useful model to investigate how marine bacteria degrade and colonize macroalgal biomass. The typical organization of polysaccharide utilization loci (PUL) is exemplified by the alginate utilization system. The genetic organization of the multi-loci carrageenan utilization system and alginate utilization system is shown, highlighting the number of proteins that have been characterized biochemically and structurally, as well as deletion mutants analyzed so far. For protein structures, the PDB accession ID is given. (Available on www.rcsb.org/.) 
indistinguishable based on in vitro biochemical assays and (ii) the role of a distal TBDT/SusD-like tandem that was absent from the main carrageenolytic locus. These results highlight the benefit of genetic tools in a bacterial model to assess gene functions in vivo. Studies on $Z$. galactanivorans also provided insights into the genomic exchange of polysaccharide degradation pathways between closely and distantly related bacteria by horizontal gene transfers (HGTs). This includes acquisitions by $Z$. galactanivorans of specific genes (e.g. alginate lyase AlyA1, endoglucanase EngA) from marine Actinobacteria and Firmicutes (Zhu et al. 2017; Dorival et al. 2018) and transfers of flavobacterial PULs to marine Proteobacteria, as well as several iconic examples of diet-mediated HGT into gut bacteria of Asian populations (Hehemann et al. 2012) (Figure 1.3).

\subsubsection{A Model to Study Bacterial Colonization of Algal Surfaces}

Besides polysaccharide degradation, Z. galactanivorans is a relevant model to study other adaptations to macroalgaeassociated lifestyle, such as surface colonization and resistance against algal defenses. First, its gliding motility and rapid spread on surfaces might aid in colonizing the algal thallus. Flow-cell chamber experiments showed that $Z$. galactanivorans can grow as thick biofilms (up to $90 \mu \mathrm{m}$ ), a capacity which is maintained or even increased in the presence of algal exudates (Salaün et al. 2012). Second, $Z$. galactanivorans possesses multiple enzymes predicted to cope with the reactive oxygen and nitrogen species produced by macroalgae as defense mechanisms. This includes superoxide dismutases, peroxidases, glutathione reductases, thioredoxins, thioredoxin reductases, peroxiredoxins and $\mathrm{NO} / \mathrm{N}_{2} \mathrm{O}$ reductases. Third, $Z$. galactanivorans features an iodotyrosine dehalogenase and biochemically active iodoperoxidases (Fournier et al. 2014) and accumulates up to $50 \mu \mathrm{M}$ of iodine, two orders of magnitude higher than typical oceanic concentrations. This distinct iodine metabolism likely participates in the resistance against the high iodine concentration in algal cell walls and the stress-induced release of halogenated compounds. Finally, Z. galactanivorans strain OII3 produces a novel secondary metabolite of the dialkylresorcinol (DAR) family, named zobelliphol, with anti-microbial activity against Gram-positive bacteria (Harms et al. 2018). This compound could therefore help $Z$. galactanivorans compete with other epiphytic bacteria. It is also possible that zobelliphol acts as an antioxidant and/or signaling molecule, similar to other DAR derivatives. In line with this, Z. galactanivorans encodes a putative acyl-homoserine lactone acylase that might degrade communication molecules produced by competing bacteria and interfere with their quorum sensing.

\subsubsection{Z. galactanivorans: Conclusions}

Collectively, all these features reveal that $Z$. galactanivorans is a multifaceted model organism to investigate how marine bacteria colonize and degrade macroalgal biomass. Such studies can improve our understanding of nutrient cycles in coastal areas but also uncover novel activities with promising biotechnological applications. Considering that marine organisms represent an immense potential reservoir of bioactive compounds, such bacterial models are essential to characterize innovative molecules of interest for biotechnology but also to understand their ecological roles.

\subsubsection{MARINOBACTER HYDROCARBONOCLASTICUS, a Model Bacterium for Biofilm Formation, Lipid Biodegradation and Iron ACQUisition}

The degradation of hydrocarbons is a bacterial activity of major industrial and environmental interest. Few microorganisms, one of which is Marinobacter hydrocarbonoclasticus, are able to efficiently degrade such compounds. Interestingly, and above the primary interest focused on hydrocarbon degradation, we will see in this section that this bacterium is also an excellent model to investigate the mechanisms of biofilm formation and iron acquisition, which are two universal and key features of microbial physiology.

\subsubsection{Key Features of Marinobacter hydrocarbonoclasticus}

Bacteria of the genus Marinobacter, to date composed of 57 species, are widespread in marine environments. They have been detected in the deep ocean, coastal seawater, marine sediment, hydrothermal settings, oceanic basalt, sea ice, solar salterns and oilfields, as well as in association with animal or algal hosts. These bacteria are Gram-stain-negative, rod-shaped, motile, mesophilic, halotolerant, heterotrophic and aerobic. The genus was first described with the type strain M. hydrocarbonoclasticus SP17 (hereafter MhSP17), which was isolated from sediments of the Mediterranean Sea near a petroleum refinery (Gauthier et al. 1992). Later, the strain M. aquaeolei VT8 (MhVT8) was isolated from the produced water of an offshore oil well and was recognized as a heterotypic synonym of $M$. hydrocarbonoclasticus (Huu et al. 1999; Márquez and Ventosa 2005). Since then, M. hydrocarbonoclasticus strains became models for studying biofilm formation on lipids and alkanes as a strategy to assimilate these insoluble substrates, production and storage of wax esters and iron acquisition through the synthesis of the siderophore petrobactin.

\subsubsection{Biofilm Formation on Nutritive Surface and Alkane Degradation}

MhSP17 exhibits a remarkable ability to grow on nearly water-insoluble compounds like long-chain alkanes (up to 32 carbons atoms), triglycerides, fatty acids and wax esters (Klein et al. 2008; Mounier et al. 2014). The water-insolubility of these substrates impairs their assimilation by bacterial cells. Growth on water-insoluble compounds can only be achieved by way of physiological and/or behavioral adaptations enabling rapid mass transfer of the substrate from the non-water-dissolved state to the cell. Biofilm formation is a widespread strategy to assimilate non-dissolved substrates, as observed, for instance, on cellulose, chitin and 
hydrocarbons (Sivadon et al. 2019). These biofilms develop on so-called nutritive interfaces since they play both the role of substrate and substratum. This feature distinguishes them from conventional biofilms growing on inert supports, such as minerals, metals or plastics. MhSP17 forms a biofilm at the interface between the aqueous phase and substrates that can be solid (saturated triacylglycerol, long-chain alkane, fatty acids, fatty alcohol and wax esters) or liquid (mediumchain alkane and unsaturated triacylglycerol). MhSP17 substrates also differ by the localization of their metabolism. Triglycerides must be hydrolyzed by a secreted lipase before entering the cell, whereas alkane metabolism is purely intracellular. The ability of MhSP17 to form biofilms on a variety of substrates exhibiting different physical properties or involving different metabolisms makes this bacterium a valuable model for studying biofilms on nutritive surfaces.

During biofilm formation on alkanes or triglyceride, MhSP17 cells undergo profound changes in gene expression, indicating a reshaping of the physiology of biofilm cells (Mounier et al. 2014; Vaysse et al. 2011, 2009). Interestingly, a great part of the genes modulated during biofilm formation was of unknown function, leading to potential for the discovery of new cellular functions. The role of some of these genes, like the alkane transport system AupA-AupB, has been elucidated by constructing mutants deleted of genes detected in omics analyses (Mounier et al. 2018). An extracellular matrix of biofilm developing on a nutritive surface is viewed as an external digester improving the solubilization of the substrate (Sivadon et al. 2019). This matrix function was documented in MhSP17 with the demonstration that the matrix contained extracellular factors involved in triglycerides and alkanes assimilation (Ennouri et al. 2017). A random mutational analysis led to the identification of a di-guanylate cyclase that is important for biofilm formation on alkane.

\subsubsection{Biosynthesis and Accumulation of Wax Esters}

The strains MhVT8 and, to a lesser extent, MhSP17 are also used as models for the biosynthesis of wax esters. Production and storage of neutral lipids such as wax esters and triacylglycerols are encountered in few marine bacterial genera like Alcanivorax and Marinobacter. This process is believed to be a survival strategy that allows bacteria to store energy and carbon to thrive in natural environments where nutrient availability fluctuates (Alvarez 2016; Manilla-Pérez et al. 2010). Wax esters are formed by the esterification of a fatty alcohol and an activated fatty acid. The length and desaturation degree of the fatty acid and the fatty alcohol moieties of wax esters confer on them diverse physicochemical properties that are of great interest in the industries of cosmetics, high-grade lubricants, wood coatings, antifoaming agents, printing inks, varnishes and food additives (Miklaszewska et al. 2018). Wax esters are nowadays mostly industrially produced from fossil fuels. The more sustainable production of wax esters by microbial cells from wastes is currently the object of intensive research and requires the utilization of model systems like M. hydrocarbonoclasticus. Strains MhVT8 and MhSP17 naturally accumulate high yields of wax esters. The two key enzymes of the biosynthesis of wax esters are the fatty acyl reductase (FAR) and the wax synthase (WS), which produce wax esters from coenzyme A (CoA) or acyl carrier protein (ACP) activated fatty acids. MhSP17 and MhVT8 possess four and five WS genes, respectively (Lenneman et al. 2013; Petronikolou and Nair 2018). Enzymatic properties of FAR and WS from Marinobacter strains have been extensively studied, leading to engineering efforts to alter their substrate specificity. The heterologous expression of these enzymes in hosts like Arabidopsis thaliana or yeasts led to the successful production of wax esters (Wenning et al. 2017; Vollheyde et al. 2020).

\subsubsection{Iron Acquisition}

In oceans, remineralization into $\mathrm{CO}_{2}$ of the organic carbon released by marine phototrophs occurs mostly through the respiration of heterotrophic bacteria (Buchan et al. 2014). A great part of the heterotrophic activity resides in the particulate fraction of the organic carbon consisting of aggregated compounds (mostly proteins, polysaccharides and lipids) that are colonized by biofilm-forming bacteria (Benner and Amon 2015). Metal availability, particularly iron, is expected to have a strong impact on organic carbon remineralization since respiration is a highly iron-demanding process, the respiratory chain alone containing approximately 94\% of the cellular iron (Tortell et al. 1999). Iron acquisition by marine heterotrophic bacteria is thus a fundamental matter to understand the recycling of organic carbon in marine environments.

MhSP17 and MhVT8 have been used as models to study iron acquisition in marine environments. MhVT8 was shown to produce three siderophores: the petrobactin and its sulfonated and disulfonated forms, while in MhSP17 culture, only petrobactin and the monosulfonated derivative were detected. The role of these sulfonations and the pathways leading to their formation are unknown. Moreover, petrobactin exhibits a typical property of marine siderophores, the photoreactivity of the ferric-complex, which causes the release of soluble $\mathrm{Fe}(\mathrm{II})$ and results in a petrobactin photoproduct that retains the capacity to complex Fe(III) (Barbeau et al. 2003). The biological significance of this photoreactivity is still not understood. Nevertheless, it might influence the iron uptake mechanism and consequently the biogeochemical cycling of iron in marine environments. It is without any doubt that the use of models that are genetically trackable will be an asset for elucidating the various mechanism facets of petrobactin and its derivatives.

\subsubsection{Genomics and Genetics of $M$. hydrocarbonoclasticus}

The genomes of MhSP17 and MhVT8 encode for 3803 and 4272 proteins, respectively. As expected for two strains from the same species, genomes of MhVT8 and MhSP17 have a great number of genes in common, their core genome consisting of 3041 genes (80\% identity, 80\% coverage). However, due to different sites of isolation and 
likely different evolutionary history, the genomes of these strains are not identical, MhVT8 and MhSP17 having 1348 and 742 strain-specific genes (80\% identity, $80 \%$ coverage), respectively. In addition, MhVT8 harbors two plasmids, pMAQU01 and pMAQU02, encoding for 213 and 201 proteins, respectively, while MhSP17 does not carry any plasmid (Singer et al. 2011).

The genomic potential of $M$. hydrocarbonoclasticus strains suggests the utilization of a large variety of substrates as terminal electron acceptors, which is consistent with their occurrence in diverse environments and the multiple lifestyles, planktonic and biofilm-forming, of this species (Singer et al. 2011). One striking feature of the M. hydrocarbonoclasticus genomes is their high content in genes involved in the metabolism of the second messenger: bis (3'-5') cyclic dimeric guanosine monophosphate (c-di-GMP). MhSP17 and MhVT8 harbor 83 and 80 genes, respectively, encoding either diguanylate cyclases with GGDEF domains that synthesize c-di-GMP or phosphodiesterases with EAL or HD-GYP domains that hydrolyze c-di-GMP. The c-di-GMP signaling pathway controls, in particular, the switch between the sessile and biofilm mode of life. The presence of a large number of c-di-GMP-related genes suggests that $M$. hydrocarbonoclasticus lifestyles are under the control of different c-di-GMP regulatory circuits that are activated in response to multiple environmental conditions.

More details about genetic tools are provided in Section 1.3 of this chapter, but specific details about Marinobacter strains are provided here. In MhSP17, gene transfer has been proved successful only by conjugation, using the transfer system based on the conjugating plasmid RP4 with an Escherichia coli donor strain expressing the transfer functions. The $M$. hydrocarbonoclasticus receiving strain was JM1, a streptomycin-resistant derivative of MhSP17 that enables counter selection in conjugation experiments. The introduction of suicide plasmids that are unable to replicate in JM1 enables random mutagenesis using mini-Tn5 transposon and site-directed mutagenesis by allele exchange. Gene addition in MhSP17 has been achieved using the transposon vector min-Tn7 that has an integration site in the MhSP17 chromosome. This has been used to express green fluorescent protein constitutively to follow fluorescent cells under fluorescence microscopy. Plasmids with the replication origin of pBBR1 are stably maintained in JM1, and the $\mathrm{P}_{\mathrm{BAD}}$ promoter was shown to be functional. This offers the possibility to introduce, maintain and express genes in MhSP17 for complementation tests or any physiological studies requiring the controlled expression of a gene (Ennouri et al. 2017; Mounier et al. 2018).

\subsubsection{Marinobacter hydrocarbonoclasticus: Conclusions}

The specific features of MhSP17 and MhVT8, such as biofilm formation on lipids and alkanes, accumulation of wax esters and production of siderophores, together with the availability of genetic tools, make them valuable models to study carbon and iron cycles in the ocean as well as to implement biotechnological processes for the production of lipids of industrial interest. In this sense, this example of a bacterial model has many common features with Zobellia galactanivorans, previously developed, and demonstrates that marine bacterial models are extremely valuable for the exploration of fundamental biological mechanisms but also for the rapidly expanding field of blue biotechnology.

\subsection{THE BACTERIAL MODEL ORGANISM TOOLKIT}

Although the four bacterial models presented have emerged from different labs, with the aim to answer diverse scientific questions concerning different biological mechanisms, they were developed thanks to a common toolkit consisting of optimized protocols for isolation and culture, genetic manipulation and phenotypic characterization. These key tools are under constant evolution and will be presented in this next section, beginning with the development of novel isolation methodologies essential for the discovery of original models and the establishment of strain collections. Then we will describe how classical genetic manipulation protocols allow the production of mutants to directly target key mechanisms of interest in bacterial models and present the state of the art genome editing CRISPR-Cas technology. Finally, we will see how recent omics approaches complement the characterization of bacterial models and pave the way for innovative phenotyping methods.

\subsubsection{Innovative TeChniques for the Isolation of New Bacterial Models: Culturing the UnCUlturable}

The decision to develop a new bacterial model may be motivated by a lack of current models that are representative of the target species and/or a particular function they carry out in the environment. The selection of this model necessarily goes through a stage of isolation and culture in the laboratory in order to fully study its phenotype and genotype or to construct mutants. However, it is well known that isolated bacteria represent only a small fraction of the total bacterial diversity and that the culturability of environmental bacteria, is very low, ranging from less than $0.001 \%$ in seawater to about $0.3 \%$ in soils (Rappé and Giovannoni 2003). Even in the era of 'meta-omic' techniques, the objective of isolating and cultivating uncultivated bacteria remains a high priority in microbiology. This phenomenon is referred to as "the great plate count anomaly", and there are many hypotheses that could explain it: (i) some bacteria do not tolerate high concentration of nutrients; (ii) organic substrates present in culture media are inappropriate for growth; (iii) important specific vitamins or growth factors are missing in the culture media; (iv) a nutritional shock is induced by an uncontrolled production of oxygen reactive species (substrate-accelerated death); (v) growth inhibition by antagonistic interaction of other species (antibiosis); (vi) some species dependent on cell-cell communication cannot grow in the absence 
of chemical signals from other cells; (vii) growth of some bacteria is too slow to be detected; and (viii) unadapted pressure, $\mathrm{O}_{2}$ concentration or inappropriate culture method (solid vs. liquid). Based on these hypotheses, different strategies can be tested to improve the isolation and cultivation of more bacterial species, especially those most abundant in the natural environment, as they could constitute interesting laboratory models.

The first strategy is to modify the culture environment and the conditions for growth. Conventional growth media are very rich in nutrients because they were originally designed for human pathogens well adapted to this type of environment. A first step is to reduce organic matter concentrations in order to favor oligotrophic species. In particular, members of Alphaproteobacteria have been shown to grow preferentially on nutrient-poor media (Senechkin et al. 2010). The reduction of the organic carbon concentration is, however, constrained: if growth is detected by observing colonies on solid media or a visible cloud in liquid media with the naked eye, a sufficient concentration of organic carbon is necessary, which would remain much higher than that of natural environments. Other studies have proposed to add peroxidase (an enzyme catalyzing the decomposition of hydrogen peroxide), to replace agar with gellan gum in solid culture media (Gelrite or Phytagel) (Tamaki et al. 2005) or to autoclave phosphate and agar in culture media separately (Kato et al. 2020, 2018). These changes could reduce the generation of hydrogen peroxide compared to conventionally prepared agar media and significantly increase the diversity of cultivable bacteria. It is also possible to complement the culture medium with components that stimulate growth, such as trace elements similar to those found in the environment, siderophores (e.g. pyoverdines-Fe, desferricoprogen), quorum sensing molecules (e.g. acylhomoserine lactone) or the supernatant of cultures of other species that stimulate the growth of others (Bruns et al. 2002; Tanaka et al. 2004). Metagenomic analysis of environmental samples can even unveil specific metabolic properties used by target non-cultivated bacteria or, inversely, the absence of genes indicating auxotrophy for certain elements that will be added to the culture medium to improve their isolation.

A second strategy is based on microculture and micromanipulation techniques. The first step consists of depositing cells from the environment on a polycarbonate membrane and then setting the membrane on a pad impregnated with nutrients or sterilized sediment. Nutrients can diffuse through the polycarbonate membrane and allow cell growth with the formation of microcolonies after a few days of incubation (Ferrari et al. 2008). Microcolonies can be observed by inverted microscopy and removed from the membrane by microdissection using ultrasound waves generated by a piezoelectric probe (Ericsson et al. 2000). Microcolonies can then be sampled using a glass capillary and transferred in tubes or microplate wells for cultivation separately from other microcolonies. This stage of microculture can then facilitate cell culture in a richer environment. This technique, however, remains tedious and requires specialized instruments.
A third strategy is to isolate single cells and try to grow them individually in order to obtain microcolonies formed of a pure culture. The separation of single cells could favour the growth of rare species, as it prevents direct competition. Obtaining microcolonies can be a first step to larger growth. Individualized cells can be grown in hundreds of diffusion chambers (called iChips) that are placed in situ in natural (e.g. sediments, soils) or simulated natural environments for the influx of natural compounds (Bollmann et al. 2010; Sizova et al. 2012; Van Pham and Kim 2014). These culture chambers are separated from the outside environment by semipermeable membranes of $0.03 \mu \mathrm{m}$, allowing fluxes of nutrients and signal molecules but preventing contamination by other microorganisms (Berdy et al. 2017; Nichols et al. 2010). This approach has been used to isolate a bacterial species producing a new antibiotic of interest (Ling et al. 2015). Another, more sophisticated approach is to encapsulate environmental bacteria into gel microdroplets (GMDs) (Liu et al. 2009), which are then placed in a chemostat fed by the nutrients extracted from the sampling environment (Zengler et al. 2002). This system also allows the transfer of communication molecules between GMDs. The GMDs in which a microcolony has developed, a priori consisting of a clonal culture, can then be separated by cell sorting using flow cytometry, followed by cultivation attempts. This device is attractive but expensive and complicated to implement and does not guarantee the long-term culturability of the selected cells.

A final strategy to cultivate environmental bacteria is the dilution-to-extinction technique. This approach emerged in the mid-1990s (Button et al. 1993) and was further developed in the 2000s (Connon and Giovannoni 2002; Stingl et al. 2007). It consists of performing serial dilutions of the samples using sterile natural sampling water or media on microplates or tubes to isolate one or a few cells in a single microchamber. The main benefit of this technique is to allow a slow and gradual adaptation (incubation for several weeks) of the bacterial cells in conditions that mimic the natural environment studied. Cell density is monitored by epifluorescence microscopy or flow cytometry counts, allowing even weak growth to be detected. In addition, the very low number of cells reduces the possibility of target uncultivated strains being overgrown and inhibited by opportunistic bacteria that may overgrow and inhibit slow growers of interest. The main drawback of this approach is the lack of interactions between cells of different species which could inhibit growth, as mentioned previously. While time consuming, this technique enabled the first-time isolation of many previously uncultured bacteria such as SAR11 or the oligotrophic marine gammaproteobacteria (OMG) that dominate marine ecosystems (Cho and Giovannoni 2004; Rappé et al. 2002; Stingl et al. 2007). The isolated species are mainly oligotrophic, and most of them fail to grow in a richer culture medium. Nevertheless, adaptations in the composition of the growth medium can allow for cultures to attain a fairly high biomass, as was the case for the model oligotrophic marine bacterium Pelagibacter ubique (Carini et al. 2013). Furthermore, additional improvements to artificial media allowed the cultivation of more than 80 
new isolates belonging to abundant marine clades SAR116, OM60/NOR5, SAR92, Roseobacter and SAR11 (Henson et al. 2016). These authors recently expanded their collection to include members of the SAR11 LD12 and Actinobacteria acIV clades and other novel SAR11 and SAR116 strains by combining a large-scale three-year dilution to extinction campaign and modelling of taxon-specific viability variation to further refine their experimental cultivation strategy (Henson et al. 2020).

\subsubsection{Genetic Manipulation of Marine Bacteria}

To fully exploit a model organism, it is important to develop molecular genetics tools to be able to elucidate the functions of genes, study and modify gene expression and engineer modified organisms for biotechnological applications. The manipulation of the strain of interest may be approached using forward or reverse genetics, depending on the research question.

Forward genetics is used when researchers are interested in a particular phenotype and seek to understand the genetic basis for this phenotype and is particularly useful for genetically intractable organisms. Either natural mutants can be studied or mutations can be induced by random mutagenesis, using chemicals or UV radiation, and then the mutations are subsequently mapped to determine the genes affected. This method was used to study the process of magnetosome formation in the magnetotactic bacterium Desulfovibrio magneticus for which genetic tools were not available (Rahn-Lee et al. 2015). The random mutagenesis toolkit was enhanced with the discovery, in the 1940s-1950s, of mobile DNA elements known as transposons, or "jumping genes", that can insert randomly into genomes, thus creating mutations. Transposons were used for the mutagenesis of a marine archaeon (Guschinskaya et al. 2016) and marine bacteria (Ebert et al. 2013; McCarren and Brahamsha 2005; Zhu et al. 2017). This method is particularly suited to largescale studies of genes of unknown function, as demonstrated by (Price et al. 2018), who generated thousands of mutant phenotypes from 32 species of bacteria.

In contrast to forward genetics, reverse genetics is based on modification of a target gene by deletion or insertion, for example, followed by the characterization of the mutant phenotype. Reverse genetics usually requires a priori knowledge of the genomic context and has been facilitated in the past 10 years owing to the increasing number of full genome sequences available (Zeaiter et al. 2018) and with the wealth of information provided by oceanic metagenomic datasets (Rusch et al. 2007; Sunagawa et al. 2015; Biller et al. 2018). Reverse genetics requires first a method to transfer foreign DNA into the target cells and then strategies for genome editing, shuttle vector and promoter design and the choice of selectable and counter-selectable markers. The toolkit can be expanded to include reporter system design to allow selection of mutated organisms or to follow gene expression. Gene inactivation is achieved primarily by homologous recombination either mediated by plasmids using the endogenous recombination machinery of the host or, more recently, by using phage recombination systems, also known as recombineering (Fels et al. 2020). Plasmid-mediated homologous recombination requires the use of traditional cloning approaches to incorporate into the plasmid vector the modified target gene with relatively long (1-2 kb) flanking homologous sequences (homology arms) that will be the site for allelic exchange for the first cross-over event. Use of a nonreplicating plasmid, under antibiotic selection, forces integration of the plasmid into the host genome via a first cross-over event. However, to achieve gene replacement, a second crossover event must occur, and these rare double-recombination events must be selected for out of the vast majority of single recombination clones that would be extremely time consuming. A strategy to promote a second cross-over event was first established with a temperature-sensitive replicon (Hamilton et al. 1989) and was later improved with the development of suicide plasmids with counter-selectable markers encoding conditional lethal genes. One of the most widely used counter-selectable markers is $s a c B$, which confers sensitivity to sucrose (Gay et al. 1985) and is lethal for cells that have not undergone a second recombination to eliminate the plasmid. This strategy was used to study the role of a specific enzyme thought to be involved in alginate digestion in the model Zobellia galactanivorans by creating a deletion mutant of an alginase lyase gene (Zhu et al. 2017).

The more recently developed methods known as recombineering, for recombination-mediated genetic engineering, integrate linear single-stranded DNA, oligonucleotides or double-stranded DNA fragments into the target genome in cells expressing the bacteriophage $\lambda$-encoded recombination proteins (see Fels et al. 2020 for a review). Recombineering offers significant advantages over plasmid-mediated methods, since it avoids laborious in vitro cloning techniques, only short homology arms are required and the recombination efficiency is high. Although this method is commonly used to engineer model organisms such as E. coli, it has been challenging to adapt to other bacteria outside of closely related enterobacteria, since the existing phage recombination systems are not efficient in all species (Fels et al. 2020). Current research is aimed at discovering new single-stranded annealing proteins that will be able to promote recombination of ssDNA in a wider range of bacteria (Wannier et al. 2020).

For all the gene editing approaches mentioned, the final hurdle for successful genome editing is the transfer of the recombinant DNA into the target strain. DNA transfer is known to occur naturally in bacteria through transformation and conjugation (Paul et al. 1991; Chen et al. 2005) and transduction (Jiang and Paul 1998) and is the mechanism for horizontal gene transfer in bacteria. Natural competence is mediated by proteins that enable the penetration of extracellular DNA, such as type IV pili or type 2 secretion systems. For example, some cyanobacterial strains (Synechococcus sp. PCC 7002) and many Vibrio strains (including isolates related to V. parahaemolyticus, V. vulnificus, V. fischeri) are naturally competent (Frigaard et al. 2004; Simpson et al. 
2019). In such cases, transformation protocols appear relatively simple and rely on incubation of the targeted strain with the exogenous DNA. Various factors can affect the efficiency of natural transformation, such as plasmid concentration, cell density, light conditions and pre-treatment of cells (Zang et al. 2007). For example, the natural competence of some Vibrio strains is induced by chitin, a biopolymer abundant in aquatic habitats, originating, for example, from crustacean exoskeletons (Meibom et al. 2005; Zeaiter et al. 2018). Tools have been developed to transform cells that are not naturally competent by artificially creating pores in the bacterial cell wall. The first artificial method to induce competency is chemical transformation, whereby treatments with salt solutions create pores in the cell membranes that allow DNA penetration into the cytoplasm. Calcium chloride, diméthylsulfoxyde, polyéthylene glycol and lysozyme are among the chemical compounds used to prepare competent cells or to improve the efficiency of other types of transformation protocols. A few positive reports of chemical transformation of marine bacteria were published. This includes transformation of Rhodobacter sphaeroides and Vibrio natriegens (Fornari and Kaplan 1982). In the latter case, it was necessary to use a $V$. natriegenes strain mutated for the chromosomal Dns endonuclease to avoid the expression of a resistance mechanism (Weinstock et al. 2016). However, several failures of chemical transformation protocols applied to marine strains were reported. For example, no transformants were obtained after testing chemical transformation protocols on 12 different Roseobacter strains (Piekarski et al. 2009). In general, chemical transformation does not appear to be a very efficient approach to transform marine bacteria (Zeaiter et al. 2018). The second method to induce competency is by electroporation, one of the most efficient tools to introduce DNA, particularly plasmid DNA, into a bacterial strain. This technique consists of the application of a brief electrical current to facilitate DNA uptake by a bacterial cell. Indeed, a brief pulse of 5-10 kV/ $\mathrm{cm}$ increases cell membrane permeability and allows the production of transformants. Marine strains belonging to diverse taxonomic groups were successfully transformed using these protocols, such as strains of Roseobacter, Vibrio, Pseudoalteromonas, Caulobacter, Halomonas and some cyanobacteria (Zeaiter et al. 2018). However, the electric treatment applied to the cells is harsh and induces large cell mortality and many transformation failures. Indeed, many factors can influence the success of an electroporation protocol, including cell concentration, the composition of the growth medium and buffer composition, temperature, voltage of electroporation systems, plasmid size and topology (Zeaiter et al. 2018). In particular, the presence of salts is one of the most influential factors on electroporation efficiency. Therefore, careful development is needed to find the best medium for electroporation of marine strains, which require high concentrations of salts for growth.

Conjugation of bacterial strains is, together with electroporation, used more often to manipulate marine strains. Conjugation is the only method of transfer that requires cell-to-cell contact, whereby a donor (usually E. coli) transfers various types of mobile elements, including plasmids, transposons and integrons. One of the advantages, compared to other methods, is the capacity to transfer large amounts of genetic material. Another advantage is that conjugation involves single-strand DNA, which avoids bacterial resistance mechanisms (restriction systems) of the receptor strain. Conjugative transfer is a complex process that requires the concerted action of many gene products. The mobile element to be transferred needs to contain an origin of transfer oriT, and the conjugative process in itself is mediated by the transfer regions tra. If the donor strain possesses tra regions, it can directly transfer the mobile element into the recipient strain via bi-parental conjugation. When the donor strain lacks these regions, a third helper strain is needed to provide conjugative ability via tri-parental conjugation. After the conjugative transfer, donor and recipient cells will both carry the mobile element. Therefore, the selection of transconjugants is a critical step after conjugation to ensure complete removal of donor (and helper) strains. This can be achieved by using selective growth conditions (e.g. salinity, temperature) favoring the growth of marine strains over donors (usually $E$. coli). Alternatively, the mobile element can encode antibiotic resistance genes controlled by promoters that function in the recipient strain but not in the donor strain. In addition, donor strains auxotrophic for a specific compound can be used. In this case, selection occurs on a culture medium devoid of the compound.

Transduction is an efficient method of transfer of DNA from a bacteriophage to a bacterium and was successfully used to transfer genes into cultivated marine isolates and natural bacterial communities (Jiang et al. 1998). However, it is not used as widely as conjugation and transformation as a DNA delivery method, since phages generally have a limited host range, and therefore requires the careful selection of suitable phages for the target bacteria strain.

\subsubsection{The Future of Gene Editing in Bacterial Models: The CRISPR-Cas Approaches}

One of the most recent additions to the genetic engineering toolbox is the CRISPR-Cas technology, also known as "molecular scissors", that allows the precise cutting of DNA at specific target sites by a Cas endonuclease, guided by a short RNA sequence known as a guide RNA (sg-RNA). The CRISPR (clustered regularly interspaced short palindromic repeats)-Cas system is an adaptive immune system in prokaryotes, defending the cell against invasion by bacteriophages or extrachromosomal elements (Barrangou et al. 2007; Bolotin et al. 2005). The CRISPR loci, present in prokaryote genomes but not those of eukaryotes or viruses (Mojica et al. 2000; Jansen et al. 2002), contain short DNA repeats separated by spacer sequences, known as protospacer sequences, that correspond to fragments of the foreign DNA that are stored as a record in the CRISPR array. Although many different CRISPR-Cas systems have been discovered (Koonin et al. 2017), the most commonly used 
system for genome editing is based on the CRISPR-Cas9 from Streptococcus pyogenes and belongs to the CRISPR type II family. It functions by transcription of the repeatspacer element to precursor CRISPR RNA (pre-crRNA), which, following base-pairing with a trans-activating crRNA (tracr-RNA), triggers processing of the structure to mature crRNA by RNAse III in the presence of Cas9 (Jinek et al. 2012). Site-specific cleavage of the foreign DNA by Cas9 only occurs (i) if there is complementary base-pairing between the cr-RNA and the protospacer and (ii) if the protospacer is adjacent to a short, sequence-specific region known as the protospacer adjacent motif (PAM) (Jinek et al. 2012). The sequence-specific cutting of the target DNA to create a double-stranded break (DSB) led the authors to realize the immediate potential of this mechanism for repurposing into a genome engineering tool, optimized further with the creation of single chimeric targeting RNA, a single guide RNA(sgRNA) to replace the cr-RNA:tracr-RNA duplex (Jinek et al. 2012). CRISPR technology revolutionized genome engineering in eukaryotes due to the ease of designing sgRNAs to guide the nuclease to the genome editing site, the efficiency of the Cas endonucleases and the possibility to scale up to multiple gene edits (see Hsu et al. 2014 and Pickar-Oliver and Gersbach 2019 for reviews). Whereas eukaryotes can use the error-prone non-homologous end-joining (NHEJ) system to repair DSBs, leading to small insertions or deletions, the majority of bacteria lack this pathway, making DSBs lethal. Although there are a number of hurdles to employing CRISPR in bacteria (Vento et al. 2019), CRISPR-Cas9 editing was successful in E. coli (Bassalo et al. 2016) and industrially important bacteria such as Lactobacillus reuteri (Oh and van Pijkeren 2014), Bacillus subtilis (Westbrook et al. 2016) and Streptomyces species (Alberti and Corre 2019). Considering the importance of streptomycete bacteria for the production of antimicrobials, several CRISPR plasmid toolkits have been developed for genome editing of Streptomyces (Alberti and Corre 2019). Examples of the application of these tools include the activation of novel transcriptionally silent biosynthetic gene clusters (BGCs) by knocking out known, preferentially or constitutively expressed BGCs (Culp et al. 2019) or the increase of their expression by "knocking in" constitutive promoters (Zhang et al. 2017). CRISPR is not limited to gene editing but can also be used to study gene repression or "knockdown" with CRISPR interference (CRISPRi). CRISPRi uses an engineered catalytically inactive (or dead) Cas9 protein (dCas9), which, instead of cutting the DNA, represses transcription of the target gene by steric interference. This approach presents several advantages, including the ease to knock down multiple genes and induction and tuning of gene repression, and requires less effort than the creation of multiple gene deletions. It has been employed for gene repression in diverse bacteria such as Streptomyces (Tong et al. 2015), Synechococcus (Knoot et al. 2020) and B. subtilis (Westbrook et al. 2016). More recently, the type V-A Cas protein, Cas12a (Cpf1) (Koonin et al. 2017), is showing promise for CRISPR editing (Yan et al. 2017) or interference in bacteria ( $\mathrm{Li}$ et al. 2018) and can be a useful alternative for when Cas9 toxicity is observed, as was the case in Streptomyces (Li et al. 2018). Cas12a presents some advantages over Cas9, since it can enable multiplex genome editing, and the production of staggered cuts instead of blunt ends by this endonuclease promotes homology-directed repair via the provision of a repair template (Paul and Montoya 2020). And, last, an alternative CRISPR system which circumvents the difficulties of repairing DSBs carries out DSB-free single-base editing using a fusion protein of a Cas9 variant, Cas9 nickase (Cas9n). This strategy allowed efficient multiplex editing in Streptomyces strains that was not possible with the standard CRISPR-Cas9 system (Tong et al. 2019) and single-base editing in Clostridium ( $\mathrm{Li}$ et al. 2019).

\subsubsection{Phenotyping and Acquiring Knowledge on Model Strains}

When the bacterial model has been isolated and preserved in appropriate conditions, and when collections of mutants have been prepared (see Section 1.3.2) to explore the role of various targeted genes and functions, the following step is to characterize in depth the model strain. Traditional phenotyping methods are still widely used in microbiology laboratories, including catabolic profiling on different nutrient sources, evaluation of growth parameters in various conditions (i.e. biofilm vs. liquid) and determination of cell shape or movements via microscopic techniques. This is especially relevant when comparing wild-type strains with mutants to evidence the role of the knocked-out genes. These traditional techniques are now complemented by the recent development of "Omics" tools providing an immense potential in model strain characterization.

First, whole-genome analysis of individual strains provides a comprehensive view of cell physiology capacities, which is an essential step when establishing a new bacterial model. Additionally, the development of genetic tools relies on thorough and precise information about gene organization and regulation in the target strain raised as a model. Accurate lists of genes, gene annotations and transcriptomic and proteomic datasets, as well as the existence of computational platforms for data integration and systems-levels analysis, are among the essential criteria to establish bacterial models (Liu and Deutschbauer 2018). An increasing quantity of genomic data for isolated strains are now available. These genomes are available in various types of databases (not specifically marine), such as that maintained by the Joint Genome Institute (JGI) Genome Portal (https://genome.jgi. doe.gov/portal/) or the one maintained by the Genoscope in France (https://mage.genoscope.cns.fr/microscope/home/ index.php). For cyanobacteria, especially marine picocyanobacteria, specific databases that include genome exploration tools are available, such as Cyanobase (http://genome.kazusa. or.jp/cyanobase) and Cyanorak (http://application.sb-roscoff. fr/cyanorak/). In some databanks, one important difficulty is that many genomes are still incomplete and published as 
"draft genomes", which can limit their utilization in genetic approaches.

The availability of numerous complete and annotated bacterial genomes in databanks facilitates the choice of the genes to knock out when starting targeted mutagenesis approaches, which is an essential step when building an isolated strain as a model of interest. Also, the existence of many genome sequences provides potential insights into bacterial metabolic pathways: genome mining of marine strains allows the putative identification and characterization of novel biosynthetic pathways (which will have then to be confirmed by other types of experimental approaches, i.e. the preparation of collections of mutants) that are responsible for the production of bioactive compounds and the identification of physiological traits that were not suspected before. Then, comparative genomics approaches may allow the comparison of specific characteristics, even in phylogenetically closed strains. For example, comparative genomics revealed that choline metabolism is widespread among marine Roseobacter. Choline is an abundant organic compound in the ocean and, through its conversion to glycine betain, serves as an osmoprotectant in many marine bacteria. This molecule is also an important component of membranes (phosphatidylcholine). However, the genetic and molecular mechanisms regulating intracellular choline and glycine betaine concentrations are poorly known in marine bacteria. Following comparative genomic analysis, a targeted mutagenesis of genes involved in choline metabolism was conducted in the model bacteria Ruegeria pomeroyi DSS-3. The authors of this study demonstrated the key role of the bet $G$ gene, encoding an organic solute transporter (essential in the uptake of choline) of the betB gene converting choline in glycine betaine and of the $f h s$ gene encoding the formyl tetrahydrofolate synthetase, essential in the oxidization of the choline methyl groups and the catabolism of glycine betaine (Lidbury et al. 2015).

While genomic analysis provides a snapshot of the physiological potential of a model strain, transcriptomics gives insights into the functions that are expressed in a given experimental condition. In the cyanobacterial Prochlorococcus strain AS9601, transcriptomics approaches revealed some of the mechanisms responsible for adaptation to salt stress. Under hypersaline conditions $(5 \% \mathrm{w} / \mathrm{v}), 1 / 3$ of the genome is differentially expressed compared to lower salt conditions $(3.8 \% \mathrm{w} / \mathrm{v})$. In hypersaline conditions, higher transcript abundance was observed for the genes involved in respiratory electron transfer, carbon fixation, osmolyte solute biosynthesis and inorganic ion transport. By contrast, a reduction of transcript abundance was noticed for the genes involved in iron transportation, heme production and photosynthesis electron transport. Such analysis thus suggests interesting mechanisms linking light utilization and salt stress in this strain of Prochlorococcus (Al-Hosani et al. 2015).

Proteomics is the characterization of the protein content in a cell using mass spectrometry and nuclear magnetic resonance approaches. Following the central dogma of molecular biology (DNA $\rightarrow$ RNA $\rightarrow$ proteins), focusing on protein expression allows an overall characterization of the organism's physiology in a defined experimental condition. Indeed, the function of many proteins has been described, and proteomics now provides to researchers in-depth characterization of the microbial cell physiology. Proteomics studies were conducted on various marine prokaryotes, including different cyanobacteria (Prochlorococcus, Synechococcus), Pseudoalteromonas, Planctomycetes, Vibrios and others (Schweder et al. 2008). For example, the planktonic/biofilm transition was investigated using proteomics in the bacterial model Pseudoalteromonas lipolytica TC8. This study revealed that peptidases, oxidases, transcription factors, membrane proteins and enzymes involved in histidine biosynthesis were over-expressed in biofilms. In contrast, proteins involved in heme production, nutrient assimilation, cell division and arginine/ornithine biosynthesis were overexpressed in planktonic cells (Favre et al. 2019). Collectively, all these data provide insights into the mechanisms that are expressed in bacterial cells and responsible for their adaptation to a biofilm or a planktonic way of life.

Metabolomics is now another essential approach to explore the physiology of prokaryotic models and their interactions with the environment. This approach provides global metabolite profiles under a given set of experimental conditions and a snapshot of the physiological response of prokaryotic cells. One important difficulty and technical challenge in metabolomics is the identification and dosage of thousands of molecular compounds, sometimes at very low concentrations, for which no standard is available for rapid identification. Untargeted metabolomic approaches compare the whole metabolomes in a qualitative or semi-quantitative manner and without a priori knowledge about the type of metabolites produced, while targeted metabolomics focuses on a particular compound. During the last decade, important improvements in the sensitivity and resolution of the analytical tools required for metabolomic analysis were achieved, including in mass spectrometry and nuclear magnetic resonance approaches (Ribeiro et al. 2019). These improvements allowed for significant progress in the characterization and identification of various compounds, including carbohydrates, alcohols, ketones, amino acids and also several types of secondary metabolites like antibiotics, pigments and infochemicals. Metabolomics is still a science in its infancy but has begun to be used to characterize the response of marine bacterial models to environmental variations. The authors of the previously mentioned study on Pseudoalteromonas lipolytica TC8 also used metabolomics to characterize the planktonic/biofilm transition. Interestingly, they revealed drastic modifications in the lipid composition of the membranes (Favre et al. 2019). Phosphatidylethanolamine derivatives were abundant in biofilm cells, while ornithine lipids were more present in planktonic bacteria. Thus, this study, with others, highlights the need to focus on membrane plasticity mechanisms in the planktonic-to-biofilm transition when bacteria attach to surfaces, which remains an underexplored research question in marine bacterial models. 


\subsection{CONCLUSIONS}

This chapter reveals, through the very different selected examples (Vibrio, Prochlorococcus and Synechococcus, Zobellia and Marinobacter), the interest and potential as well as the difficulties to establish marine bacterial strains as models for experimental biology. The isolation of bacterial strains of interest; their full characterization; the development of genetic tools and the maintenance of strain collections; the investment in genome sequencing, including accurate gene annotation; the phenotyping of mutants relying on OMIC approaches: all these steps are crucial in the establishment of new models. Clearly, it appears from this non-exhaustive list of technical approaches as well as from the collection of examples presented in this chapter that no universal experimental approach can be applied to develop a new marine bacterial model. However, unprecedented progress has been made this last decade in synthetic biology, molecular genetic tool development, the application of omics data techniques and computational tools, which undoubtedly paves the way to the development of new bacterial models of major interest to characterize many types of biological mechanisms. The potential and the outcomes of such work are immense, and applications are found in several fields. For example, recombinant marine Synechococcus allowed the production of polyunsaturated acids of medical interest (Yu et al. 2000), and recombinant strains of the marine Vibrio natriegens species contributed to the production of melanin (Wang et al. 2020). Bacterial models can also serve as tools for biology, like the model Vibrio fischeri, which serves as a biosensor to detect pollutants in diverse environmental samples (Farré et al. 2002; Parvez et al. 2006; Dalzell et al. 2002) and is often reported as one of the most sensitive assays compared to others across a wide range of chemicals. Overall, new marine bacterial models have the potential to address questions which cannot be assessed by 'traditional' bacterial models. Thus, many fundamental and applied research fields would greatly benefit from investing massively in the development of new bacterial models, including research in marine sciences, marine ecology, ecotoxicology and evolutionary studies but also 'blue' biotechnology.

\section{ACKNOWLEDGEMENTS}

François Thomas acknowledges support from CNRS and the French ANR project ALGAVOR (grant agreement ANR-18CE02-0001-01). All authors thanks Haley Flom for English grammar and spelling.

\section{BIBLIOGRAPHY}

Alberti, F., and C. Corre. 2019. Editing Streptomycete genomes in the CRISPR/Cas9 age. Natural Product Reports 36(9):12371248.

Al-Hosani, S., M. M. Oudah, A. Henschel, and L. F. Yousef. 2015. Global transcriptome analysis of salt acclimated Prochlorococcus AS9601. Microbiological Research 176:21-28.

Alvarez, H. M. 2016. Triacylglycerol and wax ester-accumulating machinery in Prokaryotes. Biochimie 120:28-39.
Bachofen, R., and A. Schenk. 1998. Quorum sensing autoinducers: Do they play a rôle in natural microbial habitats? Microbiology Research 153(1):61-63.

Barbeau, K., E. L. Rue, C. G. Trick, K. W. Bruland, and A. Butler. 2003. Photochemical reactivity of siderophores produced by marine heterotrophic bacteria and cyanobacteria based on characteristic $\mathrm{Fe}(\mathrm{III})$ binding groups. Limnology and Oceanography 48(3):1069-1078.

Barbeyron, T., S. L'Haridon, E. Corre, B. Kloareg, and P. Potin. 2001. Zobellia galactanovorans gen. nov., sp. nov., a marine species of Flavobacteriaceae isolated from a red alga, and classification of [Cytophaga] uliginosa (ZoBell and Upham 1944) Reichenbach 1989 as Zobellia uliginosa gen. nov., comb. nov. International Journal of Systematic and Evolutionary Microbiology 51(Pt 3):985-997.

Barbeyron, T., F. Thomas, V. Barbe, H. Teeling, C. Schenowitz, C. Dossat, A. Goesmann, C. Leblanc, F.-O. Glöckner, M. Czjzek, R. Amann, and G. Michel. 2016. Habitat and taxon as driving forces of carbohydrate catabolism in marine heterotrophic bacteria: Example of the model algae-associated bacterium Zobellia galactanivorans DsijT. Environmental Microbiology 18:4610-4627.

Barrangou, R., C. Fremaux, H. Deveau, M. Richards, P. Boyaval, S. Moineau, D. A. Romero, and P. Horvath. 2007. CRISPR provides acquired resistance against viruses in Prokaryotes. Science 315(5819):1709-1712.

Bassalo, M. C., A. D. Garst, A. A. L Halweg-Edwards, W. C. Grau, D. W. Domaille, V. K. Mutalik, A. P. Arkin, and R. T. Gill. 2016. Rapid and efficient one-step metabolic pathway integration in E. Coli. ACS Synthetic Biology 5(7):561-568.

Benner, R., and R. M. W. Amon. 2015. The size-reactivity continuum of major bioelements in the ocean. Annual Review of Marine Science 7(1):185-205.

Berdy, B., A. L. Spoering, L. L. Ling, and S. S. Epstein. 2017. In situ cultivation of previously uncultivable microorganisms using the ichip. Nature Protocols 12(10):2232-2242.

Biller, S. J., P. M. Berube, K. Dooley, M. Williams, B. M. Satinsky, T. Hackl, S. L. Hogle, A. Coe, K. Bergauer, and H. A. Bouman. 2018. Marine microbial metagenomes sampled across space and time. Scientific Data 5:180176.

Biller, S. J., P. M. Berube, D. Lindell, and S. W. Chisholm. 2014. Prochlorococcus: The structure and function of collective diversity. Nature Reviews Microbiology 13(1):13-27.

Blount, Z. D. 2015. The natural history of model organisms: The unexhausted potential of E. Coli. Elife 4:e05826.

Boettcher, K. J., E. G. Ruby, and M. J. McFall-Ngai. 1996. Bioluminescence in the symbiotic squid Euprymna scolopes is controlled by a daily biological rhythm. Journal of Comparative Physiology A (179):65-73.

Bollmann, A., A. V. Palumbo, K. Lewis, and S. S. Epstein. 2010. Isolation and physiology of bacteria from contaminated subsurface sediments. Applied and Environmental Microbiology 76(22):7413-7419.

Bolotin, A., B. Quinquis, A. Sorokin, and S. D. Ehrlich. 2005. Clustered regularly interspaced short palindrome repeats (CRISPRs) have spacers of extrachromosomal origin. Microbiology 151(8): 2551-2561.

Bruns, A., H. Cypionka, and J. Overmann. 2002. Cyclic AMP and acyl homoserine lactones increase the cultivation efficiency of heterotrophic bacteria from the central Baltic Sea. Applied and Environmental Microbiology 68(8):3978-3987.

Buchan, A., G. R. LeCleir, C. A. Gulvik, and J. M. Gonzalez. 2014. Master recyclers: Features and functions of bacteria associated with phytoplankton blooms. Nature Reviews Microbiology 12(10):686-698. 
Button, D. K., F. Schut, P. Quang, R. Martin, and B. R. Robertson. 1993. Viability and isolation of marine bacteria by dilution culture: Theory, procedures, and initial results. Applied and Environmental Microbiology 59(3):881-891.

Campbell, Z. T., T. O. Baldwin, and O. Miyashita. 2010. Analysis of the bacterial luciferase mobile loop by replica-exchange molecular dynamics. Biophysical Journal 99(12):4012-4019.

Carini, P., L. Steindler, S. Beszteri, and S. J. Giovannoni. 2013. Nutrient requirements for growth of the extreme oligotroph 'Candidatus Pelagibacter ubique' HTCC1062 on a defined medium. The ISME Journal 7(3):592-602.

Chen, I., P. J. Christie, and D. Dubnau. 2005. The ins and outs of DNA transfer in bacteria. Science 310(5753):1456-1460.

Cho, J.-C., and S. J. Giovannoni. 2004. Cultivation and growth characteristics of a diverse group of oligotrophic marine Gammaproteobacteria. Applied and Environmental Microbiology 70(1): 432-440.

Chun, C.-K., T. E. Scheetz, MdF. Bonaldo, B. Brown, A. Clemens, W. J. Crookes-Goodson, K. Crouch, T. DeMartini, M. Eyestone, M. S. Goodson, B. Janssens, J. L. Kimbell, T. A. Koropatnick, T. Kucaba, C. Smith, J. J. Stewart, D. Tong, J. V. Troll, S. Webster, J. Winhall-Rice, C. Yap, T. L. Casavant, M. J. McFall-Ngai, and M. Bento Soares. 2006. An annotated cDNA library of juvenile Euprymna scolopes with and without colonization by the symbiont Vibrio fischeri. BMC Genomics 7(1):154.

Chun, C.-K., J. V. Troll, I. Koroleva, B. Brown, L. Manzella, E. Snir, H. Almabrazi, T. E. Scheetz, MdF. Bonaldo, T. L. Casavant, M. Bento Soares, E. G. Ruby, and M. J. McFall-Ngai. 2008. Effects of colonization, luminescence, and autoinducer on host transcription during development of the squid-vibrio association. Proceedings of the National Academy of Sciences USA 105(32):11323-11328.

Connon, S. A., and S. J. Giovannoni. 2002. High-throughput methods for culturing microorganisms in very-low-nutrient media yield diverse new marine isolates. Applied and Environmental Microbiology 68(8):3878-3885.

Cotter, P. A., and V. J. DiRita. 2000. Bacterial virulence gene regulation: An evolutionary perspective. Annual Review of Microbiology 54(1):519-565.

Culp, E. J., G. Yim, N. Waglechner, W. Wang, A. C. Pawlowski, and G. D. Wright. 2019. Hidden antibiotics in Actinomycetes can be identified by inactivation of gene clusters for common antibiotics. Nature Biotechnology 37(10):149-154.

Dalzell, D. J. B., S. Alte, E. Aspichueta, A. De la Sota, J. Etxebarria, M. Gutierrez, C. C. Hoffmann, D. Sales, U. Obst, and N. Christofi. 2002. A comparison of five rapid direct toxicity assessment methods to determine toxicity of pollutants to activated sludge. Chemosphere 47(5):535-545.

Dorival, J., S. Ruppert, M. Gunnoo, A. Orłowski, M. ChapelaisBaron, J. Dabin, A. Labourel, D. Thompson, G. Michel, M. Czjzek, and S. Genicot. 2018. The laterally acquired GH5 Zg EngA GH5_4 from the marine bacterium Zobellia galactanivorans is dedicated to hemicellulose hydrolysis. Biochemical Journal 475(22):3609-3628.

Duarte, C. M., J. J. Middelburg, and N. Caraco. 2005. Major role of marine vegetation on the oceanic carbon cycle. Biogeosciences Discussions 2:1-8.

Dudek, M., A. Dieudonné, D. Jouanneau, T. Rochat, G. Michel, B. Sarels, and F. Thomas. 2020. Regulation of alginate catabolism involves a GntR family repressor in the marine Flavobacterium Zobellia galactanivorans DsijT. Nucleic Acids Research 48(14): 7786-7800.

Dufresne, A., L. Garczarek, and F. Partensky. 2005. Accelerated evolution associated with genome reduction in a free-living prokaryote. Genome Biology 6(2):R14.
Dufresne, A., M. Ostrowski, D. J. Scanlan, L. Garczarek, S. Mazard, B. Palenik, I. T. Paulsen, N. Tandeau de Marsac, P. Wincker, C. Dossat, S. Ferriera, J. Johnson, A. F. Post, W. R. Hess, and F. Partensky. 2008. Unraveling the genomic mosaic of a ubiquitous genus of marine Cyanobacteria. Genome Biology 9(5):R90.

Dunlap, P. V., and K. Kita-Tsukamoto. 2006. Luminous bacteria. In The Prokaryotes, edited by M. Dworkin, S. Falkow, E. Rosenberg, K.-H. Schleifer, and E. Stackebrandt, 863-892. New York, NY: Springer New York.

Dunlap, P. V., and H. Urbanczyk. 2013. Luminous bacteria. The Prokaryotes:495-521.

Earl, A. M., R. Losick, and R. Kolter. 2008. Ecology and genomics of Bacillus subtilis. Trends in Microbiology 16(6):269-275.

Eberhard, A., A. L. Burlingame, C. Eberhard, G. L. Kenyon, K. H. Nealson, and N. J. Oppenheimer. 1981. Structural identification of autoinducer of Photobacterium fischeri luciferase. Biochemistry 20(9):2444-2449.

Ebert, M., S. Laaß, M. Burghartz, J. Petersen, S. Koßmehl, L. Wöhlbrand, R. Rabus, C. Wittmann, P. Tielen, and D. Jahn. 2013. Transposon mutagenesis identified chromosomal and plasmid genes essential for adaptation of the marine bacterium Dinoroseobacter shibae to anaerobic conditions. Journal of Bacteriology 195(20):4769-4777.

Engebrecht, J., K. Nealson, and M. Silverman. 1983. Bacterial bioluminescence: Isolation and genetic analysis of functions from Vibrio fischeri. Cell 32(3):773-781.

Ennouri, H. P. d'Abzac, F. Hakil, P. Branchu, M. Naïtali, A.-M. Lomenech, R. Oueslati, J. Desbrières, P. Sivadon, and R. Grimaud. 2017. The extracellular matrix of the oleolytic biofilms of Marinobacter hydrocarbonoclasticus comprises cytoplasmic proteins and T2SS effectors that promote growth on hydrocarbons and lipids. Environmental Microbiology 19(1):159-173.

Ericsson, M., D. Hanstorp, P. Hagberg, J. Enger, and T. Nyström. 2000. Sorting out bacterial viability with optical tweezers. Journal of Bacteriology 182(19):5551-5555.

Errington, J., and L. T. van der Aart. 2020. Microbe profile: Bacillus subtilis: Model organism for cellular development, and industrial workhorse. Microbiology 166(5):425-427.

Farrant, G. K., H. Doré, F. M. Cornejo-Castillo, F. Partensky, M. Ratin, M. Ostrowski, F. D. Pitt, P. Winckler, D. J. Scanlan, D. Ludicone, S. G. Acinas, and L. Garczarek. 2016. Delineating ecologically significant taxonomic units from global patterns of marine Picocyanobacteria. Proceedings of the National Academy of Sciences USA 113(24):E3365-E3374.

Farré, M., C. Gonçalves, S. Lacorte, D. Barcelo, and M. Alpendurada. 2002. Pesticide toxicity assessment using an electrochemical biosensor with Pseudomonas putida and a bioluminescence inhibition assay with Vibrio fischeri. Analytical and Bioanalytical Chemistry 373(8):696-703.

Favre, L., A. Ortalo-Magné, L. Kerloch, C. Pichereaux, B. Misson, J.-F Briand, C. Garnier, and G. Culioli. 2019. Metabolomic and proteomic changes induced by growth inhibitory concentrations of copper in the biofilm-forming marine bacterium Pseudoalteromonas lipolytica. Metallomics 11(11):1887-1899.

Fels U., K. Gevaert, and P. Van Damme. 2020. Bacterial genetic engineering by means of recombineering for reverse genetics. Frontiers in Microbiology 11:548410.

Ferrari, B. C., T. Winsley, M. Gillings, and S. Binnerup. 2008. Cultivating previously uncultured soil bacteria using a soil substrate membrane system. Nature Protocols 3(8):1261-1269.

Ficko-Blean, E., C. Hervé, and G. Michel. 2014. Sweet and sour sugars from the sea: The biosynthesis and remodeling of sulfated cell wall polysaccharides from marine macroalgae. Perspectives in Phycology 2(1):51-64. 
Ficko-Blean, E., A. Préchoux, F. Thomas, T. Rochat, R. Larocque, Y. Zhu, M. Stam, S. Génicot, M. Jam, A. Calteau, B. Viart, D. Ropartz, D. Pérez-Pascual, G. Correc, M. Matard-Mann, K. A. Stubbs, H. Rogniaux, A. Jeudy, T. Barbeyron, C. Médigue, M. Czjzek, D. Vallenet, M. J. McBride, E. Duchaud, and G. Michel. 2017. Carrageenan catabolism is encoded by a complex regulon in marine heterotrophic bacteria. Nature Communications 8:1685.

Fidopiastis, P. M., S. von Boletzky, and E. G. Ruby. 1998. A new niche for Vibrio logei, the predominant light organ symbiont of squids in the genus Sepiola. Journal of Bacteriology 180(1):59-64.

Fidopiastis, P. M., C. M. Miyamoto, M. G. Jobling, E. A. Meighen, and E. G. Ruby. 2002. LitR, a new transcriptional activator in Vibrio fischeri, regulates luminescence and symbiotic light organ colonization. Molecular Microbiology 45(1):131-143.

Flombaum, P., J. L. Gallegos, R. A Gordillo, J. Rincon, L. L Zabala, N. Jiao, D. M. Karl, W. K. Li, M. W. Lomas, D. Veneziano, C. S. Vera, J. A. Vrugt, and A. C. Martiny. 2013. Present and future global distributions of the marine cyanobacteria Prochlorococcus and Synechococcus. Proceedings of the National Academy of Sciences USA 110(24):9824-9829.

Fornari, C. S., and S. Kaplan. 1982. Genetic transformation of Rhodopseudomonas sphaeroides by plasmid DNA. Journal of Bacteriology 152(1):89-97.

Fournier, J. B., E. Rebuffet, L. Delage, R. Grijol, L. MesletCladière, J. Rzonca, P. Potin, G. Michel, M. Czjzek, and C. Leblanc. 2014. The vanadium iodoperoxidase from the marine Flavobacteriaceae species Zobellia galactanivorans reveals novel molecular and evolutionary features of halide specificity in the vanadium haloperoxidase enzyme family. Applied and Environmental Microbiology 80(24):7561-7573.

Frigaard, N.-U., S. Yumiko, and D. A. Bryant. 2004. Gene inactivation in the cyanobacterium Synechococcus sp. PCC7002 and the green sulfur bacterium Chlorobium tepidum using in vitro-made DNA constructs and natural transformation. In Photosynthesis Research Protocols, 325-340. Totowa, NJ: Humana Press Inc.

Fuqua, W. C., S. C Winans, and E. P. Greenberg. 1994. Quorum sensing in bacteria: The LuxR-LuxI family of cell densityresponsive transcriptional regulators. Journal of Bacteriology 176(2):269-275.

Gauthier, M. J., B. Lafay, R. Christen, L. Fernandez, M. Acquaviva, P. Bonin, and J.-C. Bertrand. 1992. Marinobacter hydrocarbonoclasticus gen. nov., sp. nov., a new, extremely halotolerant, hydrocarbon-degrading marine bacterium. International Journal of Systematic Bacteriology 42(4):568-576.

Gay, P., D. Le Coq, M. Steinmetz, T. Berkelman, and C. I. Kado. 1985. Positive selection procedure for entrapment of insertion sequence elements in Gram-negative bacteria. Journal of Bacteriology 164(2):918-921.

Gram, L., H. P. Grossart, A. Schlingloff, and T. Kiorboe. 2002. Possible quorum sensing in marine snow bacteria: Production of acylated homoserine lactones by Roseobacter strains isolated from marine snow. Applied and Environmental Microbiology 68(8):4111-4116.

Grébert, T., H. Doré, F. Partensky, G. K. Farrant, E. S. Boss, and M. Picheral. 2018. Light color acclimation is a key process in the global ocean distribution of Synechococcus cyanobacteria. Proceedings of the National Academy of Sciences USA 115(9):E2010-E2019.

Greenberg, E. P., J. W. Hastings, and S. Ulitzur. 1979. Induction of luciferase synthesis in Beneckea harveyi by other marine bacteria. Archives of Microbiology 120(2):87-91.
Groisillier, A., A. Labourel, G. Michel, and T. Tonon. 2015. The mannitol utilization system of the marine bacterium Zobellia galactanivorans. Applied and Environmental Microbiology 81(5):1799-1812.

Grondin, J. M., K. Tamura, G. Déjean, D. W. Abbott, and H. Brumer. 2017. Polysaccharide utilization loci: Fuelling microbial communities. Journal of Bacteriology 199(15):e00860-16.

Guschinskaya, N., R. Brunel, M. Tourte, G. L. Lipscomb, M. W. W. Adams, P. Oger, and X. Charpentier. 2016. Random mutagenesis of the hyperthermophilic archaeon Pyrococcus furiosus using in vitro mariner transposition and natural transformation. Scientific Reports 6:36711.

Hamilton, C. M., M. Aldea, B. K. Washburn, P. Babitzke, and S. R. Kushner. 1989. New method for generating deletions and gene replacements in Escherichia coli. Journal of Bacteriology 171(9):4617-4622.

Harms, H., A. Klöckner, J. Schrör, M. Josten, S. Kehraus, M. Crüsemann, W. Hanke, T. Schneider, T. F. Schäberle, and G. M. König. 2018. Antimicrobial dialkylresorcins from marine-derived microorganisms: Insights into their mode of action and putative ecological relevance. Planta Medica 84(18):1363-1371.

Heath-Heckman, E. A. C., Suzanne M. Peyer, C. A. Whistler, M. A. Apicella, W. E. Goldman, and M. J. McFall-Ngai. 2013. Bacterial bioluminescence regulates expression of a host cryptochrome gene in the squid-vibrio symbiosis. MBio 4(2) e00167-13.

Hehemann, J.-H., G. Correc, T. Barbeyron, W. Helbert, M. Czjzek, and G. Michel. 2010. Transfer of carbohydrate-active enzymes from marine bacteria to japanese gut microbiota. Nature 464(7290):908-912.

Hehemann, J.-H., G. Correc, F. Thomas, T. Bernard, T. Barbeyron, M. Jam, W. Helbert, G. Michel, and M. Czjzek. 2012. Biochemical and structural characterization of the complex agarolytic enzyme system from the marine bacterium Zobellia galactanivorans. The Journal of Biological Chemistry 287(36):30571-30584.

Henson, M. W., D. M. Pitre, J. L. Weckhorst, V. C. Lanclos, A. T. Webber, and J. C. Thrash. 2016. Artificial seawater media facilitate cultivating members of the microbial majority from the Gulf of Mexico. Msphere 1(2):e00028-16.

Henson, M. W., V. C. Lanclos, D. M. Pitre, J. L. Weckhorst, A. M. Lucchesi, C. Cheng, ... and J. C. Thrash. 2020. Expanding the diversity of bacterioplankton isolates and modeling isolation efficacy with large-scale dilution-to-extinction cultivation. Applied and Environmental Microbiology 86(17):e00943-20.

Hollants, J., F. Leliaert, O. De Clerck, and A. Willems. 2013. What we can learn from sushi: A review on seaweed-bacterial associations. FEMS Microbiology Ecology 83(1):1-16.

Hsu, P. D., E. S. Lander, and F. Zhang. 2014. Development and applications of CRISPR-Cas9 for genome engineering. Cell 157(6):1262-1278.

Humily, F., F. Partensky, C. Six, G. K. Farrant, M. Ratin, D. Marie, and L. Garczarek. 2013. A gene island with two possible configurations is involved in chromatic acclimation in marine Synechococcus. PLoS One 8(12):e84459.

Huu, N. B., E. B. M. Denner, D. T. C. Ha, G. Wanner, and H. StanLotter. 1999. Marinobacter aquaeolei sp. nov., a halophilic bacterium isolated from a vietnamese oil-producing well. International Journal of Systematic and Evolutionary Microbiology 49(2):367-375.

Jansen, R., J. D. A. van Embden, W. Gaastra, and L. M. Schouls. 2002. Identification of genes that are associated with DNA repeats in prokaryotes. Molecular Microbiology 43(6):1565-1575. 
Ji, G., R. C. Beavis, and R. P. Novick. 1995. Cell density control of Staphylococcal virulence mediated by an octapeptide pheromone. Proceedings of the National Academy of Sciences USA 92(26):12055-12059.

Jiang, S. C., and J. H. Paul. 1998. Gene transfer by transduction in the marine environment. Applied and Environmental Microbiology 64(8):2780-2787.

Jinek, M., K. Chylinski, I. Fonfara, M. Hauer, J. A. Doudna, and E. Charpentier. 2012. A programmable dual-RNA-guided DNA endonuclease in adaptive bacterial immunity. Science 337(6096): 816-821.

Kato, S., M. Terashima, A. Yama, M. Sato, W. Kitagawa, K. Kawasaki, and Y. Kamagata. 2020. Improved isolation of uncultured anaerobic bacteria using medium prepared with separate sterilization of agar and phosphate. Microbes and Environments 35(1):ME19060.

Kato, S., A. Yamagishi, S. Daimon, K. Kawasaki, H. Tamaki, W. Kitagawa, A. Abe, M. Tanaka, T. sone, K. Asano, and Y. Kamagata. 2018. Isolation of previously uncultured slow-growing bacteria by using a simple modification in the preparation of agar media. Applied and Environmental Microbiology 84(19):e00807-18.

Klein, B., V. Grossi, P. Bouriat, P. Goulas, and R. Grimaud. 2008. Cytoplasmic wax ester accumulation during biofilm-driven substrate assimilation at the alkane-water interface by Marinobacter hydrocarbonoclasticus SP17. Research in Microbiology 159(2):137-144.

Knoot, C. J., S. Biswas, and H. B. Pakrasi. 2020. Tunable repression of key photosynthetic processes using Cas12a CRISPR interference in the fast-growing cyanobacterium Synechococcus sp. UTEX 2973. ACS Synthetic Biology 9(1):132-143.

Koonin, E. V., K. S. Makarova, and F. Zhang. 2017. Diversity, classification and evolution of CRISPR-Cas systems. Current Opinion in Microbiology 37:67-78.

Koropatnick, T. A. 2004. Microbial factor-mediated development in a host-bacterial mutualism. Science 306(5699):1186-1188.

Krasity, B. C., J. V. Troll, J. P. Weiss, and M. J. McFall-Ngai. 2011. LBP/BPI proteins and their relatives: Conservation over evolution and roles in mutualism. Biochemical Society Transactions 39(4):1039-1044.

Labourel, A., M. Jam, L. Legentil, B. Sylla, J.-H. Hehemann, V. Ferrières, M. Czjzek, and G. Michel. 2015. Structural and biochemical characterization of the laminarinase ZgLamCGH16 from Zobellia galactanivorans suggests preferred recognition of branched laminarin. Acta Crystallographica Section D Biological Crystallography 71:173-184.

Lami, R. 2019. Chapter 3: Quorum sensing in marine biofilms and environments. In Quorum Sensing, edited by Giuseppina Tommonaro, 55-96. New York, NY: Academic Press.

Lee, K.-H., and E. G. Ruby. 1994. Effect of the squid host on the abundance and distribution of symbiotic Vibrio fischeri in nature. Applied and Environmental Microbiology 60(5):1565-1571.

Lenneman, E. M., J. M. Ohlert, N. P. Palani, and B. M. Barney. 2013. Fatty alcohols for wax esters in Marinobacter aquaeolei VT8: Two optional routes in the wax biosynthesis pathway. Applied and Environmental Microbiology 79(22):7055-7062.

Li, L., K. Wei, G. Zheng, X. Liu, S. Chen, W. Jiang, and Y. Lu. 2018. CRISPR-Cpf1-assisted multiplex genome editing and transcriptional repression in Streptomyces. Applied and Environmental Microbiology 84(18):e00827-18.

Li, Q., F. M. Seys, N. P. Minton, J. Yang, Y. Jiang, W. Jiang, and S. Yang. 2019. CRISPR-Cas9D10A nickase-assisted base editing in the solvent producer Clostridium beijerinckii. Biotechnology and Bioengineering 116(6):1475-1483.

Lidbury, I., G. Kimberley, D. J. Scanlan, J. C. Murrell, and Y. Chen. 2015. Comparative genomics and mutagenesis analyses of choline metabolism in the marine Roseobacter clade. Environmental Microbiology 17(12):5048-5062.

Ling, L. L., T. Schneider, A. J. Peoples, A. L. Spoering, I. Engels, B. P. Conlon, A. Mueller, T. F. Shäberle, D. E. Hughes, S. Epstein, M. Jones, L. Lazarides, V. A. Steadman, D. R. Cohen, C. R. Felix, K. A. Fetterman, W. P. Millett, A. G. Nitti, A. M. Zullo, C. Chen, and K. Lewis. 2015. A new antibiotic kills pathogens without detectable resistance. Nature 517(7535):455-459.

Liu, H., and A. M. Deutschbauer. 2018. Rapidly moving new bacteria to model-organism status. Current Opinion in Biotechnology 51:116-122.

Liu, W., H. J. Kim, E. M. Lucchetta, W. Du, and R. F. Ismagilov. 2009. Isolation, incubation, and parallel functional testing and identification by FISH of rare microbial single-copy cells from multi-species mixtures using the combination of chemistrode and stochastic confinement. Lab on a Chip 9(15):2153.

Lombard, V., H. G. Ramulu, E. Drula, P. M. Coutinho, and B. Henrissat. 2014. The carbohydrate-active enzymes database (CAZy) in 2013. Nucleic Acids Research 42:490-495.

Manilla-Pérez, E., A. B. Lange, S. Hetzler, and A. Steinbüchel. 2010. Occurrence, production, and export of lipophilic compounds by hydrocarbonoclastic marine bacteria and their potential use to produce bulk chemicals from hydrocarbons. Applied Microbiology and Biotechnology 86(6):1693-1706.

Márquez, M. C., and A. Ventosa. 2005. Marinobacter hydrocarbonoclasticus Gauthier et al. 1992 and Marinobacter aquaeolei Nguyen et al. 1999 are heterotypic synonyms. International Journal of Systematic and Evolutionary Microbiology 55(3): 1349-1351.

Matard-Mann, M., T. Bernard, C. Leroux, T. Barbeyron, R. Larocque, A. Préchoux, A. Jeudy, M. Jam, P. N. Collén, G. Michel, and M. Czjzek. 2017. Structural insights into marine carbohydrate degradation by family GH16-carrageenases. Journal of Biological Chemistry 292(48):19919-19934.

Mazard, S., M. Ostrowski, F. Partensky, and D. J. Scanlan. 2012. Multi-locus sequence analysis, taxonomic resolution and biogeography of marine Synechococcus. Environmental Microbiology 14(2):372-386.

McCarren, J., and B. Brahamsha. 2005. Transposon mutagenesis in a marine Synechococcus strain: Isolation of swimming motility mutants. Journal of Bacteriology 187(13):4457-4462.

McFall-Ngai, M. J. 2014. The importance of microbes in animal development: Lessons from the squid-vibrio symbiosis. Annual Review of Microbiology 68:177-194.

McFall-Ngai, M. J., and E. Ruby. 1991. Symbiont recognition and subsequent morphogenesis as early events in an animal-bacterial mutualism. Science 254(5037):1491-1494.

Meibom, K. L., M. Blokesch, N. A. Dolganov, C.-Y. Wu, and G. K. Schoolnik. 2005. Chitin induces natural competence in Vibrio cholerae. Science 310(5755):1824-1827.

Miklaszewska, M., F. Dittrich-Domergue, A. Banaś, and F. Domergue. 2018. Wax synthase MhWS2 from Marinobacter hydrocarbonoclasticus: Substrate specificity and biotechnological potential for wax ester production. Applied Microbiology and Biotechnology 102(9):4063-4074.

Mojica, F. J. M., C. Díez-Villaseñor, E. Soria, and G. Juez. 2000. Biological significance of a family of regularly spaced repeats in the genomes of Archaea, Bacteria and mitochondria. Molecular Microbiology 36(1):244-246. 
Mounier, J., A. Camus, I. Mitteau, P.-J. Vaysse, P. Goulas, R. Grimaud, and P. Sivadon. 2014. The marine bacterium Marinobacter hydrocarbonoclasticus SP17 degrades a wide range of lipids and hydrocarbons through the formation of oleolytic biofilms with distinct gene expression profiles. FEMS Microbiology Ecology 90(3):816-831.

Mounier, J., F. Hakil, P. Branchu, M. Naïtali, P. Goulas, P. Sivadon, and R. Grimaud. 2018. AupA and AupB are outer and inner membrane proteins involved in alkane uptake in Marinobacter hydrocarbonoclasticus SP17. MBio 9(3):e00520-18.

Naretto, A., M. Fanuel, D. Ropartz, H. Rogniaux, R. Larocque, M. Czjzek, C. Tellier, and G. Michel. 2019. The agar-specific hydrolase $\mathrm{ZgAgaC}$ from the marine bacterium Zobellia galactanivorans defines a new GH16 protein subfamily. Journal of Biological Chemistry 294(17):6923-6939.

Nealson, K. H., T. Platt, and J. W. Hastings. 1970. Cellular control of the synthesis and activity of the bacterial luminescent system. Journal of Bacteriology 104(1):313-322.

Nedashkovskaya, O. I., M. Suzuki, M. Vancanneyt, I. Cleenwerck, A. M. Lysenko, V. V. Mikhailov, and J. Swings. 2004. Zobellia amurskyensis sp. nov., Zobellia laminariae sp. nov. and Zobellia russellii sp. nov., novel marine bacteria of the family Flavobacteriaceae. International Journal of Systematic and Evolutionary Microbiology 54(Pt5):1643-1648.

Nichols, D., N. Cahoon, E. M. Trakhtenberg, L. Pham, A. Mehta, A. Belanger, T. Kanigan, K. Lewis, and S. S. Epstein. 2010. Use of ichip for high-throughput in situ cultivation of uncultivable microbial species. Applied and Environmental Microbiology 76(8):2445-2450.

Oh, J.-H., and J.-P. van Pijkeren. 2014. CRISPR-Cas9-assisted recombineering in Lactobacillus reuteri. Nucleic Acids Research 42(17):e131.

Overmann, J., and C. Lepleux. 2016. Marine bacteria and archaea: Diversity, adaptations, and culturability. In The Marine Microbiome, 21-55. Switzerland: Springer.

Partensky, F., and L. Garczarek. 2010. Prochlorococcus: Advantages and limits of minimalism. Annual Review of Marine Science 2:305-331.

Parvez, S., C. Venkataraman, and S. Mukherji. 2006. A review on advantages of implementing luminescence inhibition test (Vibrio fischeri) for acute toxicity prediction of chemicals. Environment International 32(2):265-268.

Paul, B., and G. Montoya. 2020. CRISPR-Cas12a: Functional overview and applications. Biomedical Journal 43(1):8-17.

Paul, J. H., M. E. Frischer, and J. M. Thurmond. 1991. Gene transfer in marine water column and sediment microcosms by natural plasmid transformation. Applied and Environmental Microbiology 57(5):1509-1515.

Pearson, J. P., M. Feldman, B. H. Iglewski, and A. Prince. 2000. Pseudomonas aeruginosa cell-to-cell signaling is required for virulence in a model of acute pulmonary infection. Infection and Immunity 68(7):4331-4334.

Petronikolou, N., and S. K. Nair. 2018. Structural and biochemical studies of a biocatalyst for the enzymatic production of wax esters. ACS Catalysis 8(7):6334-6344.

Pickar-Oliver, A., and C. A. Gersbach. 2019. The next generation of CRISPR-Cas technologies and applications. Nature Reviews Molecular Cell Biology 20(8):490-507.

Piekarski, T., I. Buchholz, T. Drepper, M. Schobert, I. Wagner-Döbler, P. Tielen, and D. Jahn. 2009. Genetic tools for the investigation of Roseobacter clade bacteria. BMC Microbiology 9(1):265.

Potin, P., A. Sanseau, Y. Le Gall, C. Rochas, and B. Kloareg. 1991. Purification and characterization of a new kappa-carrageenase from a marine cytophaga-like bacterium. European Journal of Biochemistry 201(1):241-247.
Price, M. N., K. M. Wetmore, R. J. Waters, M. Callaghan, J. Ray, H. Liu, J. V. Kuehl, R. A. Melnyk, J. S. Lamson, Y. Suh, H. K. Carlson, Z. Esquivel, H. Sadeeshkumar, R. Chakraborty, G. M. Zane, B. E. Rubin, J. D. Wall, A. Visel, J. Bristow, M. J. Blow, A. P. Arkin, and A. M. Deutschbauer. 2018. Mutant phenotypes for thousands of bacterial genes of unknown function. Nature 557(7706):503-509.

Rahn-Lee, L., M. E. Byrne, M. Zhang, D. Le Sage, D. R. Glenn, T. Milbourne, R. L. Walsworth, H. Vali, and A. Komeili. 2015. A genetic strategy for probing the functional diversity of magnetosome formation. PLoS Genetics 11(1):e1004811.

Rappé, M. S., S. A. Connon, K. L. Vergin, and S. J. Giovannoni. 2002. Cultivation of the ubiquitous SAR11 marine bacterioplankton clade. Nature 418(6898):630-633.

Rappé, M. S., and S. J. Giovannoni. 2003. The uncultured microbial majority. Annual Review of Microbiology 57(1):369-394.

Rebuffet, E., A. Groisillier, A. Thompson, A. Jeudy, T. Barbeyron, M. Czjzek, and G. Michel. 2011. Discovery and structural characterization of a novel glycosidase family of marine origin. Environmental Microbiology 13(5):1253-1270.

Ribeiro, P. R., R. R. Barbosa, and C. P. de Almeida. 2019. Metabolomics approaches in microbial research: Current knowledge and perspective toward the understanding of microbe plasticity. In Microbial Interventions in Agriculture and Environment, 29-50. Singapore: Springer Nature.

Ruby, E. G., and L. M. Asato. 1993. Growth and flagellation of Vibrio fischeri during initiation of the sepiolid squid light organ symbiosis. Archives of Microbiology 159(2):160-167.

Ruby, E. G., and K. H. Nealson. 1977. A luminous bacterium that emits yellow light. Science 196(4288):432-434.

Ruby, E. G., M. Urbanowski, J. Campbell, A. Dunn, M. Faini, R. Gunsalus, P. Lostroh, C. Lupp, J. McCann, D. Millikan, A. Schaefer, E. Stabb, A. Stevens, K. Visick, C. Whistler, and E. P. Greenberg. 2005. Complete genome sequence of Vibrio fischeri: A symbiotic bacterium with pathogenic congeners. Proceedings of the National Academy of Sciences USA 102(8):3004-3009.

Rusch, D. B., A. L. Halpern, G. Sutton, K. B. Heidelberg, S. Williamson, S. Yooseph, D. Wu, J. A. Eisen, J. M. Hoffman, and K. Remington. 2007. The Sorcerer II global ocean sampling expedition: Northwest Atlantic through eastern tropical Pacific. PLoS Biology 5(3):e77.

Salaün, S., S. La Barre, M. Dos Santos-Goncalvez, P. Potin, D. Haras, and A. Bazire. 2012. Influence of exudates of the kelp Laminaria digitata on biofilm formation of associated and exogenous bacterial epiphytes. Microbial Ecology 64(2):359-369.

Sanfilippo, J. E., L. Garczarek, F. Partensky, and D. M. Kehoe. 2019. Chromatic acclimation in Cyanobacteria: A diverse and widespread process for optimizing photosynthesis. Annual Review of Microbiology 73(1):407-433.

Scanlan, D. J., M. Ostrowski, S. Mazard, A. Dufresne, L. Garczarek, W. R. Hess, A. F. Post, M. Hagemann, I. Paulsen, and F. Partensky. 2009. Ecological genomics of marine Picocyanobacteria. Microbiology and Molecular Biology Reviews 73(2):249-299.

Schweder, T., S. Markert, and M. Hecker. 2008. Proteomics of marine bacteria. Electrophoresis 29(12):2603-2616.

Senechkin, I. V., A. G. C. L. Speksnijder, A. M. Semenov, A. H. C. van Bruggen, and L. S. van Overbeek. 2010. Isolation and partial characterization of bacterial strains on low organic carbon medium from soils fertilized with different organic amendments. Microbial Ecology 60(4):829-839.

Simpson, C. A., R. Podicheti, D. B. Rusch, A. B. Dalia, and J. C. van Kessel. 2019. Diversity in natural transformation frequencies and regulation across Vibrio species. MBio 10(6):e02788-19. 
Singer, E., E. A. Webb, W. C. Nelson, J. F. Heidelberg, N. Ivanova, A. Pati, and K. J. Edwards. 2011. Genomic potential of Marinobacter aquaeolei, a biogeochemical 'opportunitroph'. Applied and Environmental Microbiology 77(8):2763-2771.

Sivadon, P., C. Barnier, L. Urios, and R. Grimaud. 2019. Biofilm formation as a microbial strategy to assimilate particulate substrates. Environmental Microbiology Reports 11(6):749-764.

Six, C., J.-C. Thomas, L. Garczarek, M. Ostrowski, A. Dufresne, N. Blot, D. J. Scanlan, and F. Partensky. 2007. Diversity and evolution of phycobilisomes in marine Synechococcus spp.: A comparative genomics study. Genome Biology 8(12):R259.

Sizova, M. V., T. Hohmann, A. Hazen, B. J. Paster, S. R. Halem, C. M. Murphy, N. S. Panikov, and S. S. Epstein. 2012. New approaches for isolation of previously uncultivated oral bacteria. Applied and Environmental Microbiology 78(1):194-203.

Stingl, U., H. J. Tripp, and S. J. Giovannoni. 2007. Improvements of high-throughput culturing yielded novel SAR11 strains and other abundant marine bacteria from the oregon coast and the Bermuda Atlantic Time Series study site. The ISME Journal 1(4):361-371.

Sunagawa, S., L. P. Coelho, S. Chaffron, J. R. Kultima, K. Labadie, G. Salazar, B. Djahanschiri, G. Zeller, D. R. Mende, and A. Alberti. 2015. Structure and function of the global ocean microbiome. Science 348(6237): 1261359.

Swartzman, A., S. Kapoor, A. F. Graham, and E. A. Meighen. 1990. A new Vibrio fischeri lux gene precedes a bidirectional termination site for the lux operon. Journal of Bacteriology 172(12):6797-6802.

Tamaki, H., Y. Sekiguchi, S. Hanada, K. Nakamura, N. Nomura, M. Matsumura, and Y. Kamagata. 2005. Comparative analysis of bacterial diversity in freshwater sediment of a shallow eutrophic lake by molecular and improved cultivation-based techniques. Applied and Environmental Microbiology 71(4): 2162-2169.

Tanaka, Y., S. Hanada, A. Manome, T. Tsuchida, R. Kurane, K. Nakamura, and Y. Kamagata. 2004. Catellibacterium nectariphilum gen. nov., sp. nov., which requires a diffusible compound from a strain related to the genus Sphingomonas for vigorous growth. International Journal of Systematic and Evolutionary Microbiology 54(3):955-959.

Thomas, F., T. Barbeyron, T. Tonon, S. Génicot, M. Czjzek, and G. Michel. 2012. Characterization of the first alginolytic operons in a marine bacterium: From their emergence in marine Flavobacteriia to their independent transfers to marine Proteobacteria and human gut Bacteroides. Environmental Microbiology 14(9):2379-2394.

Thomas, F., P. Bordron, D. Eveillard, and G. Michel. 2017. Gene expression analysis of Zobellia galactanivorans during the degradation of algal polysaccharides reveals both substratespecific and shared transcriptome-wide responses. Frontiers in Microbiology 8:1808.

Thomas, F., T. Barbeyron, and G. Michel. 2011a. Evaluation of reference genes for real time quantitative PCR in the marine flavobacterium Zobellia galactanivorans. Journal of Microbiological Methods 84:61-66.

Thomas, F., J.-H. Hehemann, E. Rebuffet, M. Czjzek, and G. Michel. 2011b. Environmental and gut Bacteroidetes: The food connection. Frontiers in Microbiology 2:93.

Thomas, F., L. C. E. Lundqvist, M. Jam, A. Jeudy, T. Barbeyron, C. Sandström, G. Michel, and M. Czjzek. 2013. Comparative characterization of two marine alginate lyases from Zobellia galactanivorans reveals distinct modes of action and exquisite adaptation to their natural substrate. The Journal of Biological Chemistry 288(32):23021-23037.
Ting, C. S., G. Rocap, J. King, and S. W. Chisholm. 2002. Cyanobacterial photosynthesis in the oceans: The origins and significance of divergent light-harvesting strategies. Trends in Microbiology 10(3):134-142.

Tong, Y., P. Charusanti, L. Zhang, T. Weber, and S. Y. Lee. 2015. CRISPR-Cas9 based engineering of Actinomycetal genomes. ACS Synthetic Biology 4(9):1020-1029.

Tong, Y., C. M. Whitford, H. L. Robertsen, K. Blin, T. S. Jørgensen, A. K. Klitgaard, T. Gren, X. Jiang, T. Weber, and S. Yup Lee. 2019. Highly efficient DSB-free base editing for Streptomycetes with CRISPR-BEST. Proceedings of the National Academy of Sciences USA 116(41):20366-20375.

Tortell, P. D., M. T. Maldonado, J. Granger, and N. M. Price. 1999. Marine bacteria and biogeochemical cycling of iron in the oceans. FEMS Microbiology Ecology 29(1):1-11.

Troll, J. V., E. H. Bent, N. Pacquette, A. M. Wier, W. E. Goldman, N. Silverman, and M. J. McFall-Ngai. 2010. Taming the symbiont for coexistence: A host PGRP neutralizes a bacterial symbiont toxin. Environmental Microbiology 12(8):21902203.

Van Pham, H. T., and J. Kim. 2014. Bacillus thaonhiensis sp. nov., a new species, was isolated from the forest soil of Kyonggi University by using a modified culture method. Current Microbiology 68(1):88-95.

van Rhijn, P., and J. Vanderleyden. 1995. The rhizobium-plant symbiosis. Microbiological Reviews 59(1):124-142.

Vaysse, P.-J., L. Prat, S. Mangenot, S. Cruveiller, P. Goulas, and R. Grimaud. 2009. Proteomic analysis of Marinobacter hydrocarbonoclasticus SP17 biofilm formation at the alkane-water interface reveals novel proteins and cellular processes involved in hexadecane assimilation. Research in Microbiology 160(10): 829-837.

Vaysse, P.-J., P. Sivadon, P. Goulas, and R. Grimaud. 2011. Cells dispersed from Marinobacter hydrocarbonoclasticus SP17 biofilm exhibit a specific protein profile associated with a higher ability to reinitiate biofilm development at the hexadecane-water interface: M. hydrocarbonoclasticus biofilmdispersed cells. Environmental Microbiology 13(3):737-746.

Vento, J. M., N. Crook, and C. L. Beisel. 2019. Barriers to genome editing with CRISPR in Bacteria. Journal of Industrial Microbiology \& Biotechnology 46(9):1327-1341.

Visick, K. L., and M. J. McFall-Ngai. 2000. An exclusive contract: Specificity in the Vibrio fischeri-Euprymna scolopes partnership. Journal of Bacteriology 182(7):1779-1787.

Vollheyde, K., D. Yu, E. Hornung, C. Herrfurth, and I. Feussner. 2020. The fifth WS/DGAT enzyme of the bacterium Marinobacter aquaeolei VT8. Lipids 55(5):479-494.

Wang, Z., T. Tschirhart, Z. Schultzhaus, E. E. Kelly, A. Chen, E. Oh, O. Nag, E. R. Glaser, E. Kim, and P. F Lloyd. 2020. Melanin produced by the fast-growing marine bacterium Vibrio natriegens through heterologous biosynthesis: Characterization and application. Applied and Environmental Microbiology 86(5): e02749-19.

Wannier, T. M., A. Nyerges, H. M. Kuchwara, M. Czikkely, D. Balogh, G. T. Filsinger, N. C. Borders, C. J. Gregg, M. J. Lajoie, X. Rios, C. Pal, and G. M. Church. 2020. Improved bacterial recombineering by parallelized protein discovery. Proceedings of the National Academy of Sciences USA 117(24):13689-13698.

Wei, S. L., and R. E. Young. 1989. Development of symbiotic bacterial bioluminescence in a nearshore cephalopod, Euprymna scolopes. Marine Biology 103(4):541-546.

Weinstock, M. T., E. D. Hesek, C. M. Wilson, and D. G. Gibson. 2016. Vibrio natriegens as a fast-growing host for molecular biology. Nature Methods 13(10):849. 
Wenning, L., T. Yu, F. David, J. Nielsen, and V. Siewers. 2017. Establishing very long-chain fatty alcohol and wax ester biosynthesis in Saccharomyces cerevisiae. Biotechnology and Bioengineering 114(5):1025-1035.

Westbrook, A. W., M. Moo-Young, and C. Perry Chou. 2016. Development of a CRISPR-Cas9 tool kit for comprehensive engineering of Bacillus subtilis. Applied and Environmental Microbiology 82(16):4876-4895.

Whitman, W. B., D. C. Coleman, and W. J. Wiebe. 1998. Prokaryotes: The unseen majority. Proceedings of the National Academy of Sciences USA 95(12):6578-6583.

Wier, A. M., S. V. Nyholm, M. J. Mandel, R. P. Massengo-Tiassé, A. L. Schaefer, I. Koroleva, S. Splinter-Bondurant, B. Brown, L. Manzella, E. Snir, H. Almabrazi, T. E. Scheetz, MdF. Bonaldo, T. L. Casavant, M. Bento Soares, J. E. Cronan, J. L. Reed, E. G. Ruby, and M. J. McFall-Ngai. 2010. Transcriptional patterns in both host and bacterium underlie a daily rhythm of anatomical and metabolic change in a beneficial symbiosis. Proceedings of the National Academy of Sciences USA 107(5):2259-2264.

Yan, M.-Y., H.-Q. Yan, G.-X. Ren, J.-P. Zhao, X.-P. Guo, and Y.-C. Sun. 2017. CRISPR-Cas12a-assisted recombineering in bacteria. Applied and Environmental Microbiology 83(17): e00947-17.

Yu, R., A. Yamada, K. Watanabe, K. Yazawa, H. Takeyama, T. Matsunaga, and R. Kurane. 2000. Production of eicosapentaenoic acid by a recombinant marine Cyanobacterium, Synechococcus sp. Lipids 35(10):1061-1064.
Zang, X., B. Liu, S. Liu, K. K. I. U. Arunakumara, and X. Zhang. 2007. Optimum conditions for transformation of Synechocystis sp. PCC 6803. The Journal of Microbiology 45(3):241-245.

Zeaiter, Z., F. Mapelli, E. Crotti, and S. Borin. 2018. Methods for the genetic manipulation of marine bacteria. Electronic Journal of Biotechnology 33:17-28.

Zengler, K., G. Toledo, M. Rappe, J. Elkins, E. J. Mathur, J. M. Short, and M. Keller. 2002. Nonlinear partial differential equations and applications: Cultivating the uncultured. Proceedings of the National Academy of Sciences USA 99(24):15681-15686.

Zhang, M. M., F. T. Wong, Y. Wang, S. Luo, Y. H. Lim, E. Heng, W. L. Yeo, R. E. Cobb, B. Enghiad, E. Lui Ang, and H. Zhao. 2017. CRISPR-Cas9 strategy for activation of silent Streptomyces biosynthetic gene clusters. Nature Chemical Biology 13(6):607-609.

Zhang, W., W. Ding, Y.-X. Li, C. Tam, S. Bougouffa, R. Wang, B. Pei, H. Chiang, P. Leung, and Y. Lu. 2019. Marine biofilms constitute a bank of hidden microbial diversity and functional potential. Nature Communications 10(1):1-10.

Zhu, Y., F. Thomas, R. Larocque, N. Li, D. Duffieux, L. Cladière, F. Souchaud, G. Michel, and M. J. McBride. 2017. Genetic analyses unravel the crucial role of a horizontally acquired alginate lyase for brown algal biomass degradation by Zobellia galactanivorans. Environmental Microbiology 19(6):2164-2181. 